\title{
Uma análise acerca do boicote dos estudantes aos exames de avaliação da educação superior
}

\author{
Thiago Leitão, Gabriela Moriconi, Mariangela Abrão, Dayse Silva \\ Ministério da Educação, Instituto de Estudos e Pesquisas Anísio Teixeira
}

\section{Introdução}

A Lei de Diretrizes e Bases da Educação Nacional (LDBEN), lei n. 9.394, de 20 de dezembro de 1996 (Brasil, 1996), prioriza os processos de avaliação visando à melhoria da qualidade do ensino, propondo critérios para a regulação do setor. A partir da sanção da LDB, a avaliação da educação superior assume lugar de destaque dentre as políticas educacionais, seja como norteadora de suas diretrizes mais amplas, seja como orientadora de ações efetivas dos agentes governamentais.

Um sistema de avaliação da educação superior deve ter como objetivo principal oferecer informações de qualidade para subsidiar a tomada de decisões de indivíduos e organizações direta ou indiretamente envolvidos com esse nível do sistema educacional.

Em linhas gerais, podem ser apontados como principais interessados de um sistema de avaliação da educação superior: os atuais e os potenciais alunos e suas famílias, os futuros empregadores dos profissionais egressos desses cursos, os agentes reguladores, as próprias instituições de ensino superior e os profissionais que nelas atuam. ${ }^{1}$

O principal - mas não necessariamente único - interesse dos alunos (atuais e potenciais), de suas famílias e dos empregadores está diretamente relacionado aos resultados finais dos cursos, ou seja, está em identificar quais cursos formam indivíduos com melhores condições de serem bons profissionais no mercado de trabalho. Isso porque, de posse dessas informações, os potenciais alunos podem escolher as instituições em que tentarão ingressar, relacionando com essas informações aspectos como preço e localização, entre outros; os atuais alunos podem utilizar os bons resultados de seu curso ao se candidatar a uma vaga de estágio e/ou de emprego e os maus resultados para cobrar melhorias da instituição de ensino; e os futuros empregadores

${ }^{1}$ Para Harvey e Newton (2004), a beleza da abordagem, do ponto de vista do governo, é que a garantia de qualidade assegura não só a responsabilização, mas pode ser usada para motivar um grau de cumprimento das políticas públicas ou para controlar a expansão do setor privado. 
têm mais um subsídio para decidir qual profissional contratar.

Para as instituições de ensino superior, para os profissionais que nelas atuam e para os órgãos reguladores, medir somente a qualidade do profissional egresso dos cursos não é suficiente, pois a qualidade desse profissional não é um indicador direto do trabalho da instituição. Um curso que recebe alunos com formação prévia deficiente pode realizar um excelente trabalho, mas, ainda assim, não ter seus ex-alunos entre os melhores profissionais. Para Dias, Horiguela e Marchelli (2006, p. 461), mesmo as instituições que recebem os alunos menos preparados se empenhem na recuperação dos deficits de aprendizagem, elas terão poucas chances de se equiparar às instituições que recebem os alunos mais bem preparados. Para eles, "a qualidade do aluno é essencialmente diferente da qualidade de ensino, mas ambas se confundem na prática”.

Portanto, é muito importante saber o quanto o curso contribui para a formação dos alunos, permitindo que as instituições de ensino alterem suas práticas caso constatem pouca contribuição dos cursos aos seus respectivos alunos e que os reguladores definam critérios mínimos de qualidade para orientar essas instituições e, se necessário, aplicar sanções.

O Brasil é o único país a aplicar um exame nacional de cunho obrigatório aos estudantes como um dos principais instrumentos que compõem o sistema de avaliação da educação superior.

Entretanto, tal instrumento de avaliação, por vezes, é contestado por alunos e instituições por ser demasiadamente dependente do aluno. Na mídia, encontram-se declarações de estudantes que afirmam ser injusto o peso que esse exame coloca sobre eles, já que o objetivo final é avaliar o curso, e não o aluno. Em contrapartida, algumas instituições de ensino superior reclamam que os alunos não teriam nenhum incentivo para se comprometer com a prova, o que afetaria o resultado de seus cursos.

Para Paiva (2008, p. 42), “a implantação de políticas públicas de avaliação da educação superior brasileira é atividade que, indiscutivelmente, desencadeia manifestações favoráveis e críticas severas".
Somente a avaliação contínua dessas políticas e a realização dos ajustes necessários é que asseguram o sucesso e a manutenção delas. $\mathrm{O}$ autor ainda afirma que a avaliação do desempenho acadêmico, enquanto um dos componentes da política pública de avaliação da educação superior brasileira, por meio de exame nacional, não é atividade pouco complexa. O sucesso do processo depende sobremaneira do comprometimento de todos os sujeitos envolvidos. Entretanto, os estudantes destacam-se como os membros mais importantes quando a avaliação em questão é de desempenho acadêmico.

O fato é que toda aplicação de prova para avaliação do ensino superior (inicialmente o Exame Nacional de Cursos - ENC ou Provão, e posteriormente o Exame Nacional de Desempenho dos Estudantes - ENADE) gera discussões sobre uma provável falta de participação ou envolvimento dos alunos no processo avaliativo - comumente denominado boicote.

O objetivo do presente artigo é, portanto, avaliar esse boicote. $\mathrm{O}$ texto está dividido em três seções. A primeira aborda a avaliação dos cursos de ensino superior no Brasil. A seção seguinte expõe a análise dos dados referentes ao boicote e, em seguida, são apresentadas as considerações finais.

\section{A avaliação dos cursos de ensino superior no Brasil}

O processo de avaliação da educação superior no Brasil se dá por meio do Sistema Nacional da Avaliação da Educação Superior (SINAES), ${ }^{2}$ criado em 14 de abril de 2004 como substituto do modelo de avaliação implantado em 1996, o Exame Nacional de Cursos ou Provão, ${ }^{3}$ e objetiva aferir tanto a qualidade acadêmica do profissional egresso quanto a contribuição do curso para a sua formação.

${ }^{2}$ Sobre as bases para o SINAES, ver Brasil (2003).

${ }^{3}$ Para uma análise mais ampla sobre as principais alterações ocorridas do Provão ao ENADE, consultar Verhine, Dantas e Soares (2006). 
Os principais instrumentos de avaliação de cursos do SINAES são o ENADE e a avaliação in loco, esta última feita por especialistas que visitam as instituições de ensino superior. Os processos de avaliação são coordenados pela Comissão Nacional de Avaliação Superior (CONAES); o Instituto Nacional de Estudos e Pesquisas Educacionais Anísio Teixeira (INEP) é responsável pela parte operacional desse processo.

O ENADE é um exame aplicado aos alunos ingressantes ${ }^{4}$ e concluintes ${ }^{5}$ de cursos de graduação de áreas definidas anualmente pelo Ministério da Educação (MEC), com periodicidade trienal de aplicação a cada curso. O exame é composto de quarenta questões, sendo dez da parte de formação geral, comum aos estudantes de todos os cursos selecionados, e trinta do componente específico, diferenciado para cada um dos cursos de graduação. Ambas as provas contêm questões discursivas e de múltipla escolha nas duas partes. Além do caderno de provas recebido no momento da realização do exame, os alunos selecionados recebem previamente em sua residência um questionário socioeconômico que deve ser preenchido e entregue no dia da prova.

Até 2008, o ENADE era realizado por amostragem, ${ }^{6}$ e o INEP elaborava a amostra dos participantes a partir da inscrição dos alunos habilitados a fazer a prova pela própria instituição de ensino superior. A participação do estudante selecionado no ENADE é condição indispensável para a emissão do histórico escolar, em que é registrada a data na qual o aluno realizou o exame. O estudante que não foi selecionado

${ }^{4}$ São considerados estudantes ingressantes (primeiro ano do curso) aqueles alunos que, até a data determinada pelo INEP, tiverem concluído entre $7 \%$ e $22 \%$ da carga horária mínima do currículo do curso da IES.

${ }^{5}$ São considerados estudantes concluintes (último ano do curso) aqueles que, até a data determinada pelo INEP, tiverem concluído pelo menos $80 \%$ da carga horária mínima do currículo do curso da IES ou todo aquele aluno que se encontre na possibilidade de concluir o curso no respectivo ano letivo.

${ }^{6}$ Segundo o INEP, a partir de 2009, o ENADE passará a ser realizado em caráter universal. no processo de amostragem não é obrigado a fazer o ENADE e tem como registro no seu histórico escolar os seguintes dizeres: "dispensado do ENADE pelo MEC nos termos do artigo 5o da lei n. 10.861/2004".

Portanto, todo aluno selecionado é obrigado a comparecer no dia da prova para, no mínimo, assinar seu nome e devolver o material em branco. Caso contrário, não poderá receber o diploma enquanto não regularizar a situação no INEP por meio de justificativa ou realizando a prova de formação geral no ano seguinte.

A partir das notas no ENADE dos alunos de cada curso, é gerado o Conceito ENADE, ${ }^{7}$ um índice de 1 a 5 atribuído aos cursos. Como a mesma prova é aplicada para alunos concluintes e ingressantes dos cursos, é possível usar esses dados para calcular o Indicador de Diferença entre os Desempenhos Observado e Esperado (IDD) ${ }^{8}$ - a diferença entre a nota obtida pelos concluintes e a nota que seria esperada (baseada na nota dos ingressantes). O IDD é, na verdade, uma medida da contribuição do curso para o desempenho de seus estudantes no ENADE.

Aos resultados do ENADE e do IDD soma-se um componente de insumos ${ }^{9}$ para a construção do Conceito Preliminar de Cursos (CPC) ${ }^{10}$ que possui como função principal a orientação dos avaliadores institucionais e a racionalização das avaliações in loco na atribuição do Conceito de Curso. O CPC é um índice com escala de 1 a 5 que permite a dispensa dessa avaliação caso o resultado seja maior do que

${ }^{7}$ Para detalhes do cálculo do Conceito ENADE, ver Nota Técnica do ENADE, disponível em: <http:/Enade.inep.gov.br/ EnadeResultado/site/resultados/pesquisaResultados.faces $>$.

${ }^{8}$ Para detalhes do cálculo do IDD, ver Nota Técnica do IDD, disponível em: <http://www.inep.gov.br/areaigc/>

${ }^{9}$ O componente insumos é construído com informações relacionadas à titulação e ao regime de trabalho do corpo docente e à percepção dos alunos em relação à infraestrutura do curso e sua organização pedagógica.

10 Para detalhes do cálculo do CPC, ver Nota Técnica do CPC, disponível em: <http:/Enade.inep.gov.br/EnadeResultado/ pdfs/Procedimentos_Metodologicos_Calculo.pdf $>$ 
$2 .{ }^{11}$ Caso haja visita in loco, o Conceito de Curso será definido pelos avaliadores. Os cursos com CPC 3 e 4, objetivando melhora desse resultado, podem solicitar a visita, mas, caso o Conceito de Curso divirja do CPC, é necessária uma justificação dos motivos.

\section{Análise dos alunos que adotaram o boicote}

Antes da análise descritiva e econométrica dos dados trabalhados, é necessária a explicação da construção da amostra para a criação dos bancos de dados.

Como foi descrito, até 2008 o ENADE era realizado de forma amostral. Portanto, do total de alunos ingressantes ou concluintes dos cursos de graduação avaliados em determinado ciclo, apenas uma parcela era selecionada para participar da prova. Apesar da obrigatoriedade do exame para a obtenção do diploma, existe ainda uma parcela de alunos que não comparece para realizá-lo, ${ }^{12}$ ficando em situação irregular com o MEC. Como forma de captar a intenção do aluno em promover o boicote, foram considerados neste estudo apenas os alunos selecionados e presentes na aplicação do exame. Pensou-se ainda que a ausência dos alunos poderia representar uma forma de insatisfação em relação ao processo avaliativo, e isso poderia ser caracterizado também como uma forma de boicote. Mas, uma vez que o exame possui caráter obrigatório, punitivo aos ausentes, essa não seria uma estratégia viável de demonstrar tal insatisfação. Além do que não seria possível diferenciar os alunos insatisfeitos e que adotaram essa estratégia de manifestação dos alunos que, por qualquer outro motivo, gostariam de participar do exame, mas não conseguiram comparecer no momento da realização.

${ }^{11}$ Caso não fosse instituído o CPC, todos os cursos avaliados pelo ENADE deveriam receber visita in loco a cada ciclo trienal. Isso resultaria em cerca de 9.800 visitas por ciclo, cerca de 3.260 visitas/ano e cerca de 270 visitas/mês, o que tornaria esse procedimento operacionalmente inviável.

12 Mais à frente esse tema será abordado de forma mais ampla.
Apesar de se falar muito em boicote ao ENADE, não há uma definição oficial do que pode ser considerado boicote propriamente dito. Neste estudo são consideradas duas possibilidades de demonstração de que os alunos teriam aderido ao boicote. A primeira engloba apenas os participantes que colam adesivos, escrevem mensagens contra o exame ou fazem qualquer tipo de registro explícito que demonstre a sua posição contrária. Esse grupo é identificado pelos aplicadores ${ }^{13}$ do exame pela variável "tipo de presença na prova" como "protesto". A segunda engloba os participantes que não responderam nenhuma questão dos quatro componentes da prova ${ }^{14} \mathrm{e}$ são identificados como "prova em branco".

Com isso, assume-se que os participantes que deixaram as provas totalmente em branco, juntamente com aqueles que expressaram sua manifestação de forma explícita, não tiveram a intenção de contribuir com o processo avaliativo, o que foi considerado uma forma de boicote. ${ }^{15}$

${ }^{13} \mathrm{O}$ exame é realizado por empresas contratadas pelo INEP por processo de licitação pública.

${ }^{14}$ Os componentes do exame são: Formação geral - múltipla escolha; Formação geral - discursiva; Componente específico múltipla escolha; Componente específico - discursiva.

${ }^{15}$ Outras duas formas de caracterizar os aderentes ao boicote foram pensadas neste trabalho. Uma seria incluir nesse grupo de pessoas os alunos que responderam algum item da prova, mas obtiveram nota bruta da prova - média ponderada da nota Formação geral (25\%) e nota Componente específico (75\%) padronizados em escala de 0 a 100 - igual a 0 . O outro grupo de alunos que também poderia ser considerado aderente ao boicote seria aquele que entrega as partes discursivas em branco e tira menos que $20 \%$ nas partes objetivas do exame, caracterizado por aqueles alunos que aparentemente apenas se dispuseram a comparecer ao local da prova, assinar a folha de presença, entregar a parte discursiva em branco e passar o tempo obrigatório de presença em sala assinalando aleatoriamente o caderno de resposta dos componentes objetivos. A justificativa para que não fossem adotados esses dois tipos de comportamento como boicote é que não seria possível distinguir desse grupo de pessoas aqueles que realizaram o exame de forma efetiva e objetivaram contribuir com o processo avaliativo, mas, por razões diversas, enquadravam- 


\section{Análise descritiva}

Antes de passar à análise da ocorrência de boicotes na prova do ENADE, é importante apresentar o tamanho da amostra utilizada, referente aos alunos selecionados e presentes na prova dentre aqueles habilitados e inscritos pelas respectivas instituições de ensino. Os dados apresentados, as tabelas e figuras têm como fonte os microdados do INEP/MEC.

\section{Ausência às provas}

Na Tabela 1 estão representados os percentuais de ausentes e presentes para os anos de 2005, 2006 e 2007. Observa-se que, nos anos analisados, o percentual de ausentes se manteve menor que $17 \%$ e que o ano de 2006 apresentou o maior percentual, com 16,46\%.

Tabela 1: Total de alunos selecionados, presentes e ausentes no ENADE

\begin{tabular}{|c|c|c|c|c|c|}
\hline Ano & $\begin{array}{c}\text { Total de } \\
\text { selecionados }\end{array}$ & $\begin{array}{c}\text { Total de } \\
\text { presentes }\end{array}$ & $\begin{array}{c}\% \text { de } \\
\text { presentes }\end{array}$ & $\begin{array}{c}\text { Total de } \\
\text { ausentes }\end{array}$ & $\begin{array}{c}\% \text { de } \\
\text { ausentes }\end{array}$ \\
\hline 2005 & 323.338 & 277.476 & $85,82 \%$ & 45.862 & $14,18 \%$ \\
\hline 2006 & 462.658 & 386.524 & $83,54 \%$ & 76.134 & $16,46 \%$ \\
\hline 2007 & 215.419 & 189.614 & $88,02 \%$ & 25.805 & $11,98 \%$ \\
\hline
\end{tabular}

Na Figura 1 são apresentados os percentuais de ausência de alunos dentre aqueles inscritos e selecionados para realizar a prova separados em ingressantes e concluintes. Como pode ser observado, em todos os anos avaliados houve maior ausência por parte dos alunos ingressantes do que dos concluintes em todas as comparações, com exceção dos alunos de instituições públicas em 2006. O percentual de alunos ingressantes que não compareceu ao exame foi especialmente significativo em 2006, passando de $20 \%$. Pode-se supor que essa ausência seja explicada pelo fato de o aluno ingressante que falta ao exame ter ainda um período de três anos para regularizar a situação. Cabe ressaltar ainda que o aluno em situação irregular não compõe a amostra considerada, ou seja, não contribui para o resultado da avaliação.

se nesses grupos de alunos representantes desses comportamentos. Além disso, a representatividade desses dois tipos de comportamento não se revela muito expressiva, quando comparada com os outros tipos de boicote (protesto e prova em branco).
Figura 1: Percentual de alunos selecionados ausentes no ENADE de 2005, 2006 e 2007

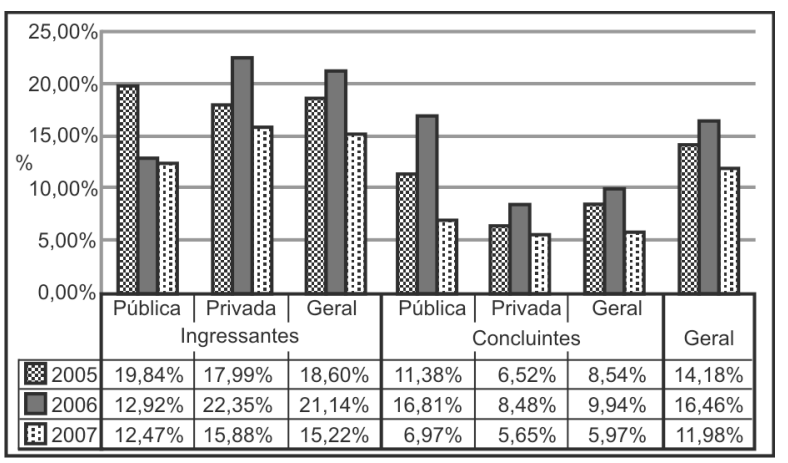

Analisando a Figura 2, é possível observar que o período de aplicação do ENADE apresentou maior percentual de ausência quando comparado ao Provão, com o ano de 2006 ocupando o maior percentual de ausência (9,94\%). Para essa comparação, a proporção de ausentes no ENADE só considera os concluintes, visto que no Provão os ingressantes não eram avaliados.

$\mathrm{O}$ alto percentual encontrado em 2006 pode estar relacionado aos cursos avaliados. Como na metodologia de avaliação do Provão todos os cursos eram avaliados anualmente, enquanto no ENADE a avaliação ocorre em um período trienal, não é possível comparar o comportamento de ausência apresentado nos anos do ENADE com os demais anos analisados. Apenas no ano de 2004, cujos cursos foram reavaliados em 2007, pode-se identificar que o percentual de ausência é similar, mostrando que essa tendência comportamental se manteve. Da mesma forma, a comparação dos anos de 2005 e 2006 só será válida quando analisados os anos de 2008 e 2009.

Figura 2: Percentual de alunos concluintes ausentes no Provão e no ENADE

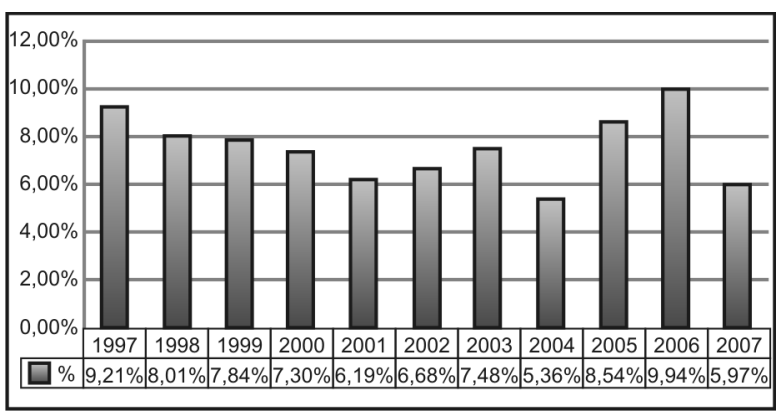




\section{Ocorrências de boicote}

Como pode ser observado na Figura 3, o percentual de boicote nunca foi superior a 3,5\% para o total da população avaliada em todos os anos de aplicação tanto do Provão (1997 a 2003) quanto do ENADE (2004 a 2007). Interessante notar a variabilidade desse percentual quando comparado aos anos de realização do ENADE, indicando que esse comportamento pode estar diretamente associado aos cursos avaliados em cada ano do ciclo.

Figura 3: Percentual de boicote

(1997 a 2007)

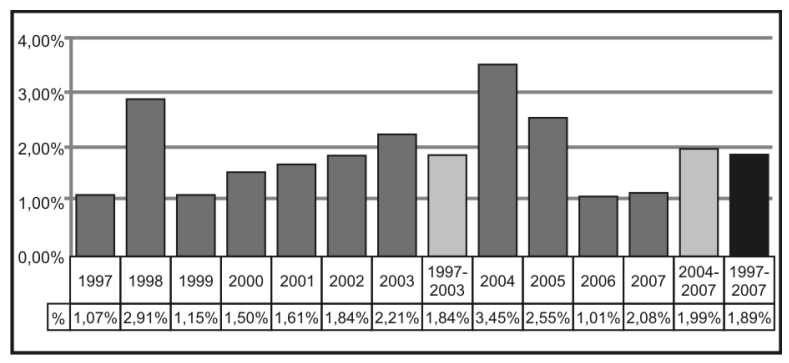

Modalidades de boicote

A Figura 4 apresenta as ocorrências das modalidades de boicote por tipo de instituição (pública e privada). Nota-se que "prova em branco" foi a modalidade mais utilizada de boicote ao longo do processo avaliativo. Outro fato que pode ser constatado nessa análise é que os alunos das instituições públicas, em quase todos os anos avaliados, utilizaram mais a modalidade de boicote "protesto" do que os alunos das instituições privadas.

Figura 4: Modalidade de boicote por ano

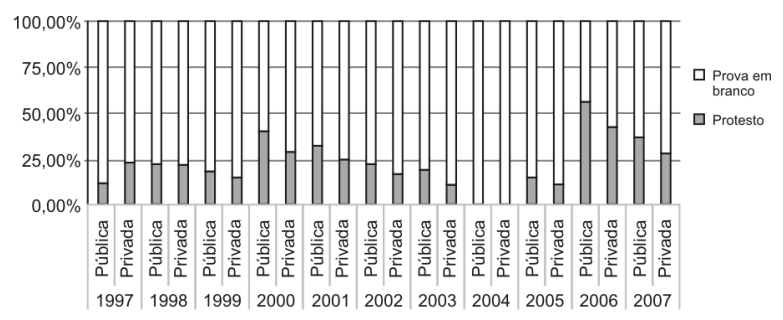

\section{Análise do boicote por cursos}

A Figura 5 exibe o total de boicote dos cursos avaliados nos anos 2005, 2006 e 2007. Observa-se que, apesar de o percentual total de boicote não ultrapassar 3,5\% dos alunos presentes e selecionados, esse índice varia de forma bastante acentuada entre os cursos avaliados. No curso de Ciências Sociais, por exemplo, esse percentual chegou a mais de $13 \%$, enquanto nos cursos de Engenharia Grupo IV (Química) e Engenharia Grupo VII (Grupo Misto I) não houve nenhum boicote registrado.

As figuras seguintes apresentam os percentuais de boicote nos cursos avaliados para as instituições de ensino público e para as instituições de ensino privado.

Na Figura 6, nota-se que os cursos de Serviço Social, Terapia Ocupacional, Fonoaudiologia, Arquitetura e Urbanismo, Comunicação Social e Ciências Sociais de instituições de ensino superior públicas apresentaram total de boicote maior que $15 \%$. Na Figura 7, considerando-se as instituições do setor privado, com exceção dos cursos de Ciências Sociais (7\%) e Serviço Social $(5,5 \%)$, os demais cursos apresentaram percentual de boicote abaixo de $5 \%$.

Os cursos de Biomedicina, Ciências Contábeis, Engenharia Grupo III, Engenharia Grupo IV, Engenharia Grupo VIII e Tecnologia em Agroindústria, nas instituições públicas, e de Agronomia, Biomedicina, Medicina, Ciências Contábeis, Direito, Medicina Veterinária e Tecnologia em Radiologia, nas instituições privadas, foram retirados das figuras por apresentarem percentual de boicote inferior a $0,2 \%$.

As análises das Figuras 6 e 7 indicam mais uma vez que há grande diversidade na dimensão de adesão ao boicote por curso avaliado. A proporção de boicote chega a representar mais de $35 \%$ dos alunos selecionados e presentes em alguns cursos, isoladamente, e $0 \%$ em outros. Outro fator bastante claro nessa análise se refere ao comportamento do 
Figura 5: Total de boicote por curso (2005, 2006 e 2007)

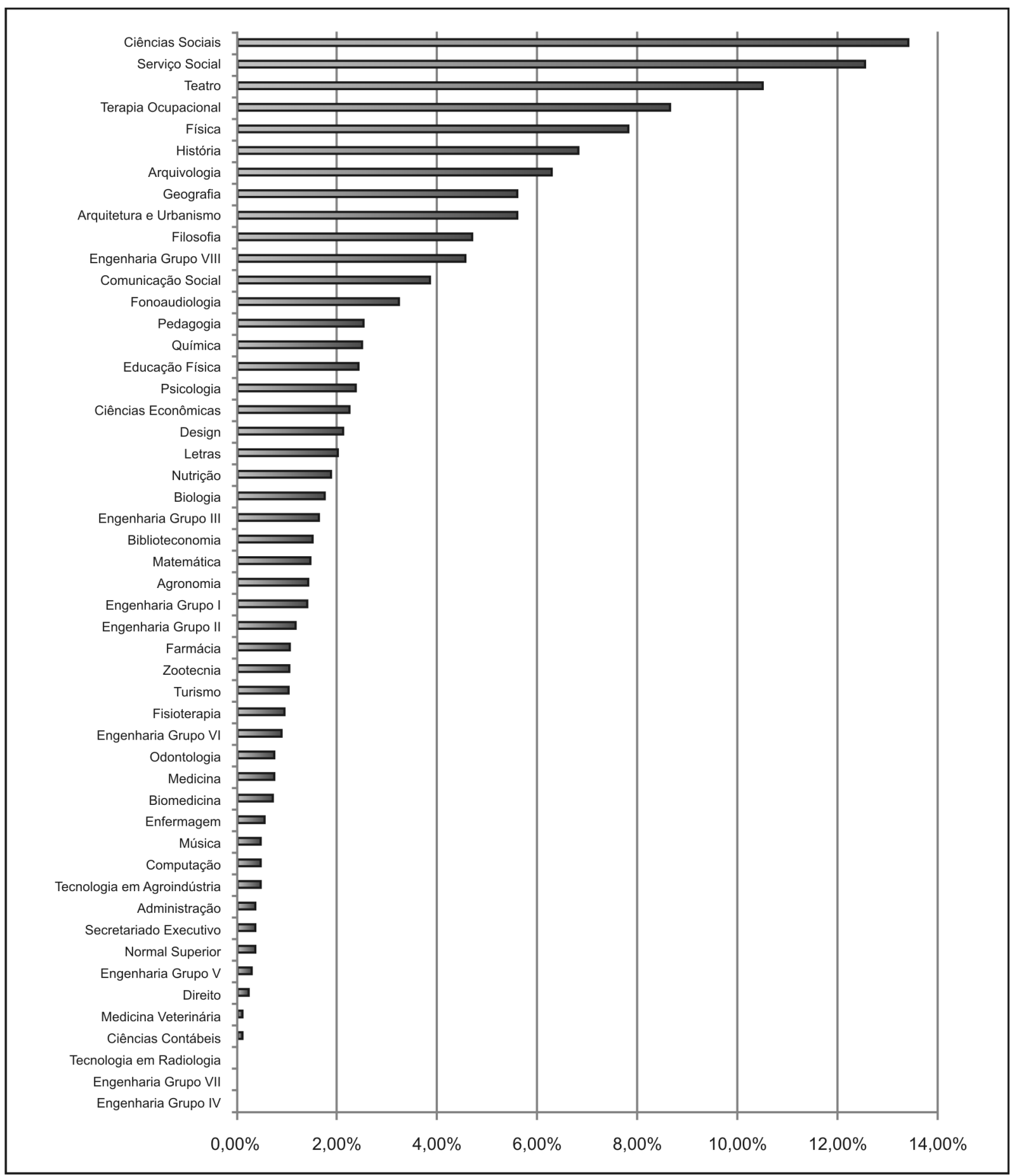

aluno em relação ao exame, quando comparado entre as categorias administrativas da IES (instituição de ensino superior). Nota-se que o comportamento de boicote é muito mais adotado pelos alunos das instituições públicas de ensino superior, quando comparado aos alunos das instituições privadas. 
Figura 6: Percentuais de "protesto" e "prova em branco" por curso, calculados em relação ao total de alunos participantes das instituições públicas

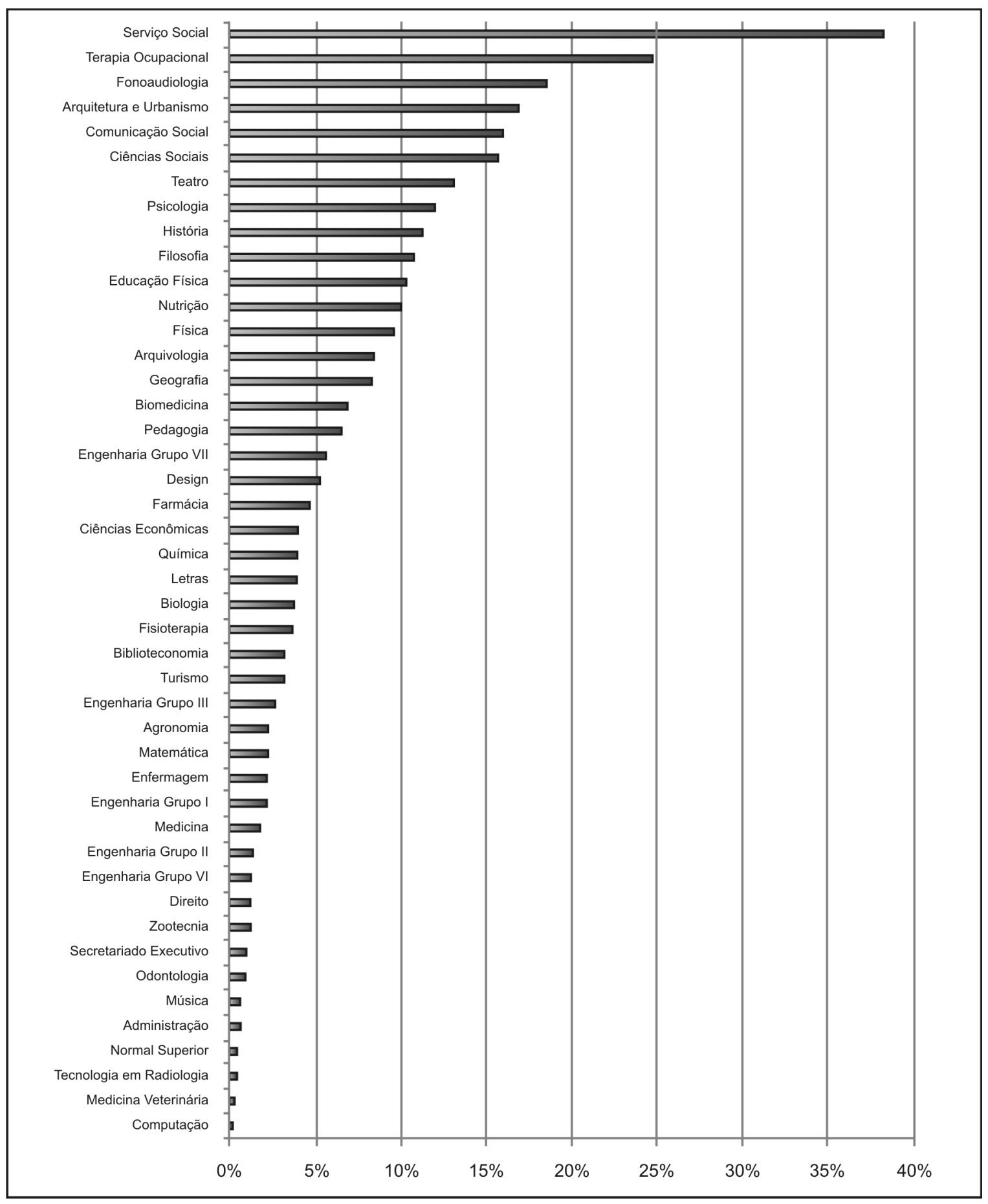


Figura 7: Percentuais de "protesto" e "prova em branco" por curso, calculados em relação ao total de alunos participantes das instituições privadas

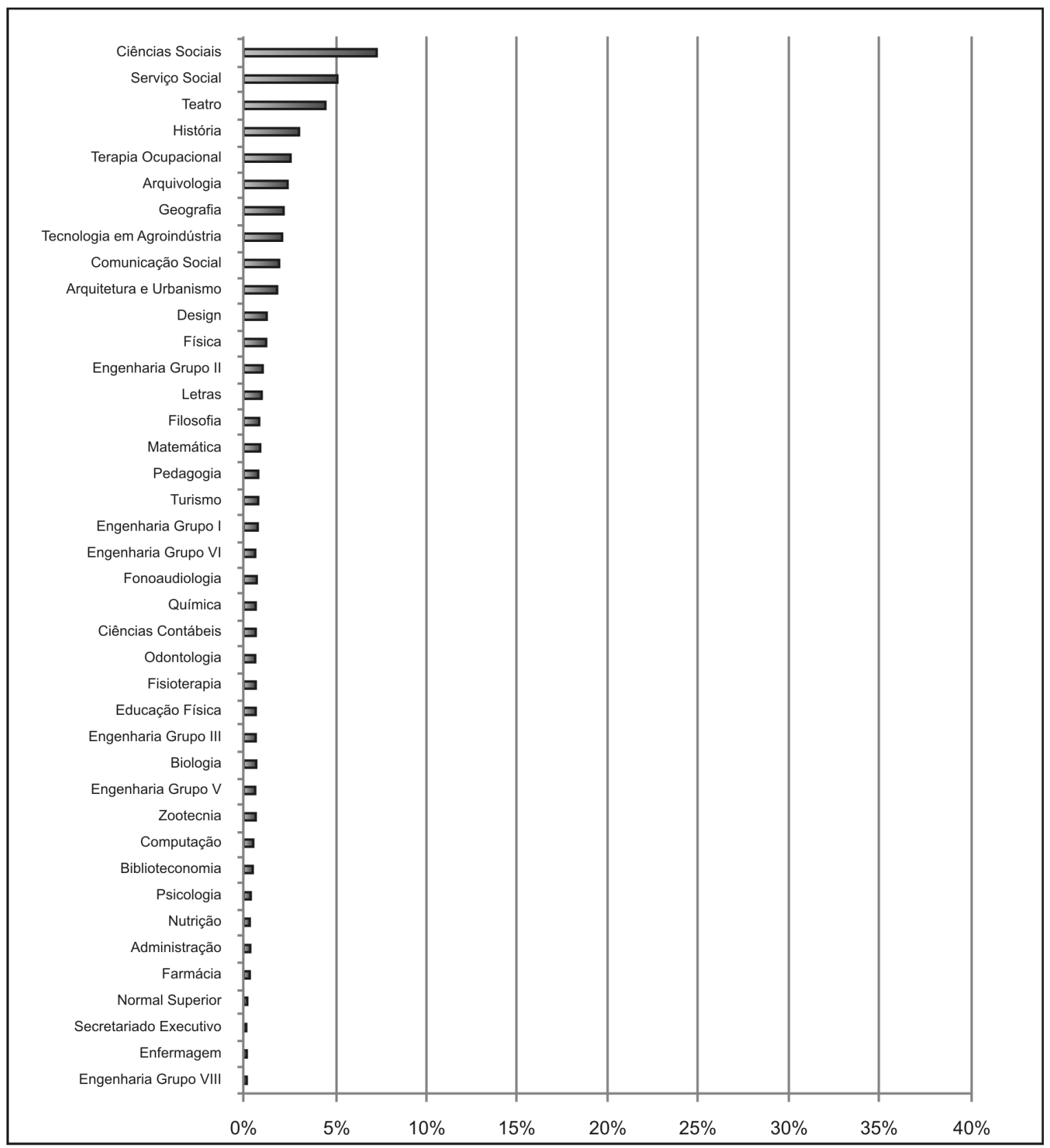

Análise do perfil do boicotante ${ }^{16}$

Para a análise dos dados, considerou-se, em todos os itens, o perfil dos estudantes selecionados que

${ }^{16}$ Para facilitar a referência ao estudante que adere ao boicote, optamos por denominá-lo boicotante. compareceram para realizar o exame em 2005, 2006 e 2007. O termo "geral" foi utilizado para definir o perfil da amostra dos respondentes.

Diversas variáveis foram utilizadas nessa análise, e a seguir serão demonstrados os resultados daquelas de maior interesse. As informações utilizadas foram extraídas do questionário socioeconômico do ENADE. 
Tabela 2: Perfil dos alunos em geral e dos alunos boicotantes

\begin{tabular}{|l|c|c|c|c|}
\hline \multirow{2}{*}{ Variáveis } & \multicolumn{2}{|c|}{ Geral - \% } & \multicolumn{2}{c|}{ Boicotantes - \% } \\
\cline { 2 - 5 } & Pública & Privada & Pública & Privada \\
\hline Masculino & 42,98 & 39,18 & 40,52 & 44,59 \\
\hline Brancos & 64,95 & 72,28 & 62,43 & 66,65 \\
\hline $\begin{array}{l}\text { Renda familiar até 3 salários } \\
\text { mínimos }\end{array}$ & 30,99 & 29,64 & 27,00 & 25,24 \\
\hline $\begin{array}{l}\text { Renda familiar mais de 3 a 10 } \\
\text { salários mínimos }\end{array}$ & 46,38 & 47,83 & 48,27 & 44,29 \\
\hline $\begin{array}{l}\text { Renda familiar mais de 10 a } \\
\text { 20 salários mínimos }\end{array}$ & 15,89 & 15,64 & 17,25 & 19,16 \\
\hline $\begin{array}{l}\text { Renda familiar mais de 20 } \\
\text { salários mínimos }\end{array}$ & 6,73 & 6,90 & 7,48 & 11,30 \\
\hline Exerce atividade remunerada & 56,19 & 69,51 & 49,18 & 66,00 \\
\hline $\begin{array}{l}\text { Escolaridade do pai - até } \\
\text { ensino fundamental }\end{array}$ & 46,32 & 51,54 & 36,16 & 39,70 \\
\hline $\begin{array}{l}\text { Escolaridade do pai - ensino } \\
\text { médio }\end{array}$ & 28,51 & 28,34 & 34,07 & 30,48 \\
\hline $\begin{array}{l}\text { Escolaridade do pai - ensino } \\
\text { superior }\end{array}$ & 25,17 & 20,12 & 29,77 & 29,82 \\
\hline $\begin{array}{l}\text { Tipo de escola em que cursou } \\
\text { o ensino médio - maior parte } \\
\text { em pública }\end{array}$ & 55,18 & 62,09 & 46,53 & 49,60 \\
\hline $\begin{array}{l}\text { Tipo de escola em que cursou } \\
\text { o ensino médio - maior parte } \\
\text { em privada }\end{array}$ & 42,39 & 33,85 & 51,35 & 45,51 \\
\hline $\begin{array}{l}\text { Tipo de escola em que cursou } \\
\text { o ensino médio - metade em } \\
\text { pública e metade em privada }\end{array}$ & 2,43 & 4,06 & 2,12 & 4,89 \\
\hline $\begin{array}{l}\text { Região do curso que frequen- } \\
\text { ta - Norte }\end{array}$ & 7,79 & 4,45 & 7,32 & 5,45 \\
\hline $\begin{array}{l}\text { Região do curso que frequen- } \\
\text { ta - Nordeste }\end{array}$ & 30,25 & 11,32 & 29,48 & 20,89 \\
\hline $\begin{array}{l}\text { Região do curso que frequen- } \\
\text { ta - Centro-Oeste }\end{array}$ & 12,61 & 8,45 & 6,13 & 11,25 \\
\hline $\begin{array}{l}\text { Região do curso que frequen- } \\
\text { ta - Sudeste }\end{array}$ & 26,88 & 56,83 & 36,28 & 46,33 \\
\hline Região do curso que frequen- & 22,47 & 18,95 & 20,79 & 16,08 \\
\hline
\end{tabular}

Verificou-se que a maior parte dos estudantes selecionados é do sexo feminino, tanto nas instituições públicas quanto nas instituições privadas. Quando se analisa o gênero da população que boicota, vê-se que o percentual de mulheres é levemente superior nessa população para as instituições públicas.

Quanto à cor da pele, a maioria dos respondentes é branco - formada pelos que se declararam brancos, amarelos e índios - (64,95\% na pública e $72,28 \%$ na privada). Contudo, observa-se que esse mesmo percentual não é verificado na população que boicota, sendo esta representada por $62,43 \%$ e $66,65 \%$ de brancos nas instituições públicas e privadas, respectivamente.

Quanto à renda familiar, a maior parte dos respondentes está na faixa de 3 a 10 salários mínimos na pública $(46,38 \%)$ e na privada $(47,83 \%)$. Há duas situações que merecem análise: primeiro, pode-se verificar que o percentual de boicotantes, tanto na rede pública quanto na privada, é maior para as faixas de renda mais altas quando comparado com a população em geral. Segundo, vê-se que os boicotantes da rede privada têm renda superior aos da rede pública, fator esse não observado para os alunos em geral.

Com relação à ocupação dos estudantes, nota-se que os boicotantes, tanto das instituições públicas quanto das privadas, são proporcionalmente mais representados por indivíduos que não trabalham do que a média em geral.

Considerando a formação escolar dos pais ${ }^{17}$ dos boicotantes, verifica-se que eles são mais escolarizados do que a média geral, tanto na pública, quanto na privada. O percentual de respondentes cujos pais têm educação superior é de $25,17 \%$ na pública e $20,12 \%$ na privada para a população em geral, enquanto esse percentual é de $29,77 \%$ e $29,82 \%$ para os boicotantes das instituições públicas e privadas, respectivamente.

A maioria dos participantes do exame cursou a maior parte do ensino médio em escola pública (55,18\% dos respondentes da pública e 62,09\% da privada). Esses percentuais possuem uma dimensão mais reduzida quando observada a população boicotante.

Considerando-se que o ENADE é um exame nacional, a amostra (selecionados) contempla todas as regiões do país. A maior concentração de estudantes está nas regiões Sudeste, Sul e Nordeste.

Chama a atenção o fato de que o percentual de selecionados das instituições públicas que frequentam seu curso na região Sudeste é de 26,88\%; entretanto,

\footnotetext{
${ }^{17}$ Essa mesma análise foi feita para escolaridade das mães,
} mas, como os resultados apresentaram a mesma tendência, optou-se por expor apenas os dados relacionados aos pais. 
$36,28 \%$ dos alunos que aderiram ao boicote nessa categoria administrativa são dessa região. $\mathrm{O}$ mesmo se apresenta na região Nordeste para as instituições privadas, em que somente $11,32 \%$ dos participantes frequentam seu curso nessa região e $20,89 \%$ do total de boicotantes das instituições privadas estão representados nessa região.

A partir da análise descritiva, observa-se que o perfil socioeconômico do estudante aderente ao boicote não difere muito do perfil socioeconômico do aluno médio. Apenas as variáveis "renda familiar", "escolaridade do pai" e "tipo de escola em que cursou o ensino médio" apresentaram diferenças consideráveis, mostrando que os boicotantes são alunos com maior renda familiar, possuem pais mais escolarizados e cursaram mais a maior parte do ensino médio em escola privada, quando comparados aos alunos em geral. Além disso, esses estudantes avaliam pior seu curso ou instituição.

\section{Percepção da instituição e do curso}

A intenção desta análise é verificar o nível de satisfação do aluno boicotante com seu curso e/ou IES, comparando-o com os alunos em geral. Como pode ser observado na Tabela 3, o aluno que boicota o exame avalia pior os quesitos "instalações físicas", "espaço pedagógico", “equipamentos disponíveis", "laboratórios", "currículos", "procedimentos de ensino" e “domínio das disciplinas pelos professores", quando comparados à média geral. Além disso, os alunos boicotantes das instituiçõs públicas se mostram muito mais críticos que os boicotantes das IES privadas.

Tabela 3: Porcentagem de respondentes que avaliam negativamente a IES, os professores e o curso por tipo de boicote

\begin{tabular}{|l|c|c|c|c|c|c|}
\hline \multirow{2}{*}{ Quesito } & \multicolumn{2}{|c|}{ Geral } & \multicolumn{2}{c|}{ Protesto } & \multicolumn{2}{c|}{ Em branco } \\
\cline { 2 - 7 } & Pública & Privada & Pública & Privada & Pública & Privada \\
\hline $\begin{array}{l}\text { Instalações } \\
\text { físicas }\end{array}$ & 26,86 & 6,84 & 37,11 & 15,26 & 38,03 & 15,08 \\
\hline $\begin{array}{l}\text { Espaço peda- } \\
\text { gógico }\end{array}$ & 20,37 & 7,23 & 28,83 & 13,45 & 28,48 & 13,14 \\
\hline $\begin{array}{l}\text { Equipamen- } \\
\text { tos disponí- } \\
\text { veis }\end{array}$ & 41,32 & 16,33 & 52,04 & 25,37 & 54,29 & 25,71 \\
\hline
\end{tabular}

(continuação)
\begin{tabular}{|l|c|c|c|c|c|c|}
\hline \multicolumn{1}{|c}{ Quesito } & \multicolumn{2}{|c|}{ Geral } & \multicolumn{2}{c|}{ Protesto } & \multicolumn{2}{c|}{ Em Branco } \\
\cline { 2 - 7 } & Pública & Privada & Pública & Privada & Pública & Privada \\
\hline $\begin{array}{l}\text { Equipa- } \\
\text { mentos de } \\
\text { laboratório }\end{array}$ & 18,84 & 4,21 & 29,74 & 9,88 & 29,4 & 7,95 \\
\hline $\begin{array}{l}\text { Currículo do } \\
\text { curso }\end{array}$ & 13,46 & 7,32 & 22,94 & 15,41 & 18,78 & 13,08 \\
\hline $\begin{array}{l}\text { Procedimen- } \\
\text { tos de ensino } \\
\text { utilizados } \\
\text { pelos profes- } \\
\text { sores }\end{array}$ & 10,23 & 4,44 & 12,7 & 11,06 & 13,93 & 8,45 \\
\hline $\begin{array}{l}\text { Domínio das } \\
\text { disciplinas } \\
\text { pelos profes- } \\
\text { sores }\end{array}$ & 7,33 & 3,7 & 8,64 & 7,92 & 10,03 & 6,75 \\
\hline
\end{tabular}

Análise econométrica

Com objetivo de verificar as variáveis que estariam relacionadas a maiores ocorrências de boicote dos alunos que participam do ENADE, foi realizada uma análise econométrica utilizando a metodologia de regressão logit. Esse tipo de análise permite identificar o impacto isolado de determinada variável em relação à prática de boicote. Os dados utilizados nessa análise são provenientes dos bancos de dados e resultados do ENADE e do questionário socioeconômico para os anos de 2005, 2006 e 2007.

Como variável dependente, foi construída uma variável binária que assumiu o valor "1", caso o indivíduo tivesse boicotado (foram considerados os dois tipos de boicote: "protesto" e "prova em branco"), e o valor "0", em caso contrário. Como variáveis independentes, foram utilizadas informações pessoais sobre o indivíduo (idade, gênero, estado civil, cor da pele, renda familiar, ocupação, escolaridade dos pais, tipo de escola em que cursou o ensino médio e assuntos que mais lê no jornal), bem como informações sobre a condição do indivíduo no curso (ingressante ou concluinte, região do curso que frequenta, se é ou foi bolsista, dedicação acadêmica, percepção dos aspectos físicos, pedagógicos e curriculares do curso, categoria administrativa da instituição e curso que frequenta). ${ }^{18}$

${ }^{18}$ Para detalhes sobre a construção das variáveis independentes utilizadas na análise, consultar o Anexo A. 
As informações referentes aos indivíduos dos cursos Engenharia Grupo IV (Química), Engenharia Grupo V (Materiais), Engenharia Grupo VII (Grupo Misto I), Tecnologia em Radiologia e Tecnologia em Agroindústria foram excluídas da análise por apresentarem número muito reduzido de boicote. Os resultados dessa estimação estão expostos no Anexo B.

Os gráficos a seguir apresentam o impacto de cada uma das variáveis independentes de interesse no boicote. Os gráficos foram obtidos a partir do seguinte procedimento: foram considerados os coeficientes das variáveis provenientes do logit inicial. A partir daí, atribuiu-se o nível mínimo da variável que seria analisada para todos os indivíduos da amostra. Calculou-se então a probabilidade de boicote de cada indivíduo e obteve-se a média dessas probabilidades. Esse resultado mostrou qual era a média das probabilidades de boicote, caso todos os indivíduos possuíssem o nível mínimo da variável analisada. Então, atribuiu-se um nível acima do mínimo da variável analisada a todos os indivíduos da amostra. Novamente foram calculadas as probabilidades individuais de boicote. Com esses resultados, obteve-se a média das probabilidades de boicote, caso todos os indivíduos possuíssem um nível a mais nessa característica analisada. E assim sucessivamente, até o nível mais alto do atributo que foi considerado.

Por exemplo, a variável de renda familiar possui quatro níveis diferentes de renda: até 3 salários mínimos, de 3,1 a 10 salários mínimos, de 10,1 a 20 salários mínimos e mais de 20 salários mínimos. Primeiramente substituíram-se as informações no banco de dados, de tal forma que a variável renda_3_sal possuísse apenas valor igual a "1" e as variáveis renda_3_10_sal, renda_10_20_sal e renda_20_mais_sal possuíssem apenas valor igual a "0". Com os resultados dos coeficientes obtidos na estimação inicial, calcularam-se as novas probabilidades de boicote para cada indivíduo e obteve-se a média dessas probabilidades. Esse resultado mostrou a média das probabilidades de boicote, caso todos os indivíduos possuíssem renda familiar de até 3 salários mínimos. Em seguida, substituíram-se as informações no banco de dados de tal forma que a variável renda_3_10_sal possuísse apenas valor igual a "1" e as outras variáveis de renda familiar, renda_3_sal, renda_10_20_sal e renda_20_mais_sal, possuíssem apenas valor igual a " 0 ”. Utilizando-se novamente os coeficientes da regressão inicial, foram calculadas as probabilidades individuais de boicote e obteve-se a média dessas probabilidades. Nesse segundo passo foi obtida a média das probabilidades de boicote, caso todos os indivíduos possuíssem o segundo menor nível de renda familiar (de mais de 3 até 10 salários mínimos). Fazendo esse mesmo exercício para todos os níveis de renda, foram obtidas as médias das probabilidades de boicote para cada um dos quatro diferentes níveis de renda.

Resultados das variáveis referentes às instituições e à condição do aluno na instituição

Um fator bastante importante na probabilidade de boicote é a categoria administrativa da IES. Os resultados mostram que a diferença desse fator isolado representa um incremento de cerca de 2,5 pontos percentuais na probabilidade de o aluno boicotar.

Figura 8: Probabilidade de boicote por categoria administrativa da IES

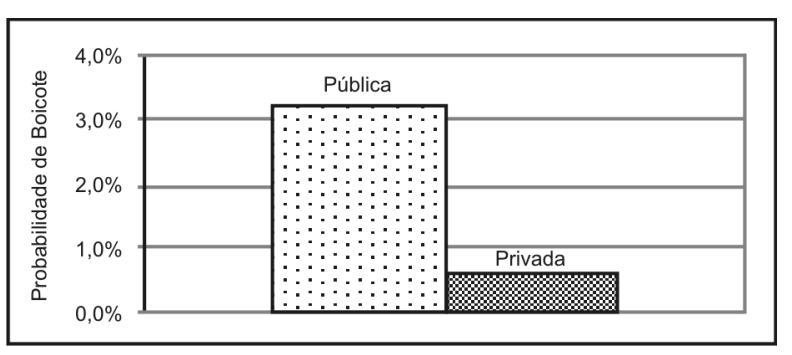

Notou-se que o fato de o aluno ser ingressante é correlacionado à prática de boicote, embora a correlação não seja expressiva. 
Figura 9: Probabilidade de boicote por situação do aluno

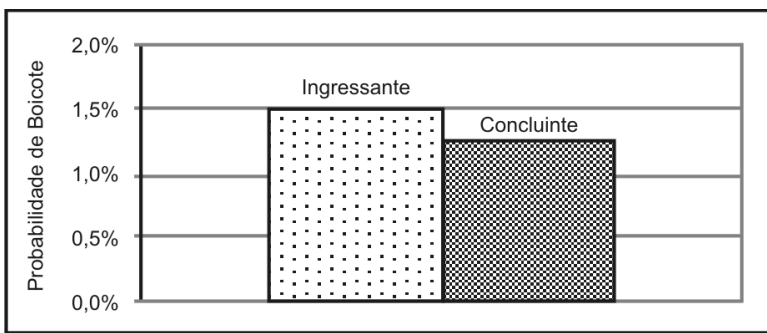

Outra análise de interesse foi avaliar a probabilidade de boicote por curso. Pode-se observar claramente que há grande variação de probabilidade de boicote quando os cursos são analisados individualmente.
É interessante notar a diferença existente entre o gráfico apresentado na Figura 10 e o gráfico apresentado na Figura 5. Na Figura 10, a probabilidade de boicote por curso está controlada por diversas outras variáveis, enquanto a Figura 5 apresenta a porcentagem de boicote por curso sem qualquer tipo de controle. Para explicitar essa diferença, pode-se tomar o curso de Arquivologia como exemplo: de acordo com a Figura 5, esse era o sétimo curso com maior porcentagem de boicote. $\mathrm{Na}$ Figura 10, vê-se que esse curso passou para a décima sexta posição na probabilidade de boicote. Como esse curso possui apenas alunos em instituições públicas, o resultado da Figura 5 pode mostrar a relação entre o curso e a ocorrência de boicote, mas também o fato

Figura 10: Probabilidade de boicote por curso

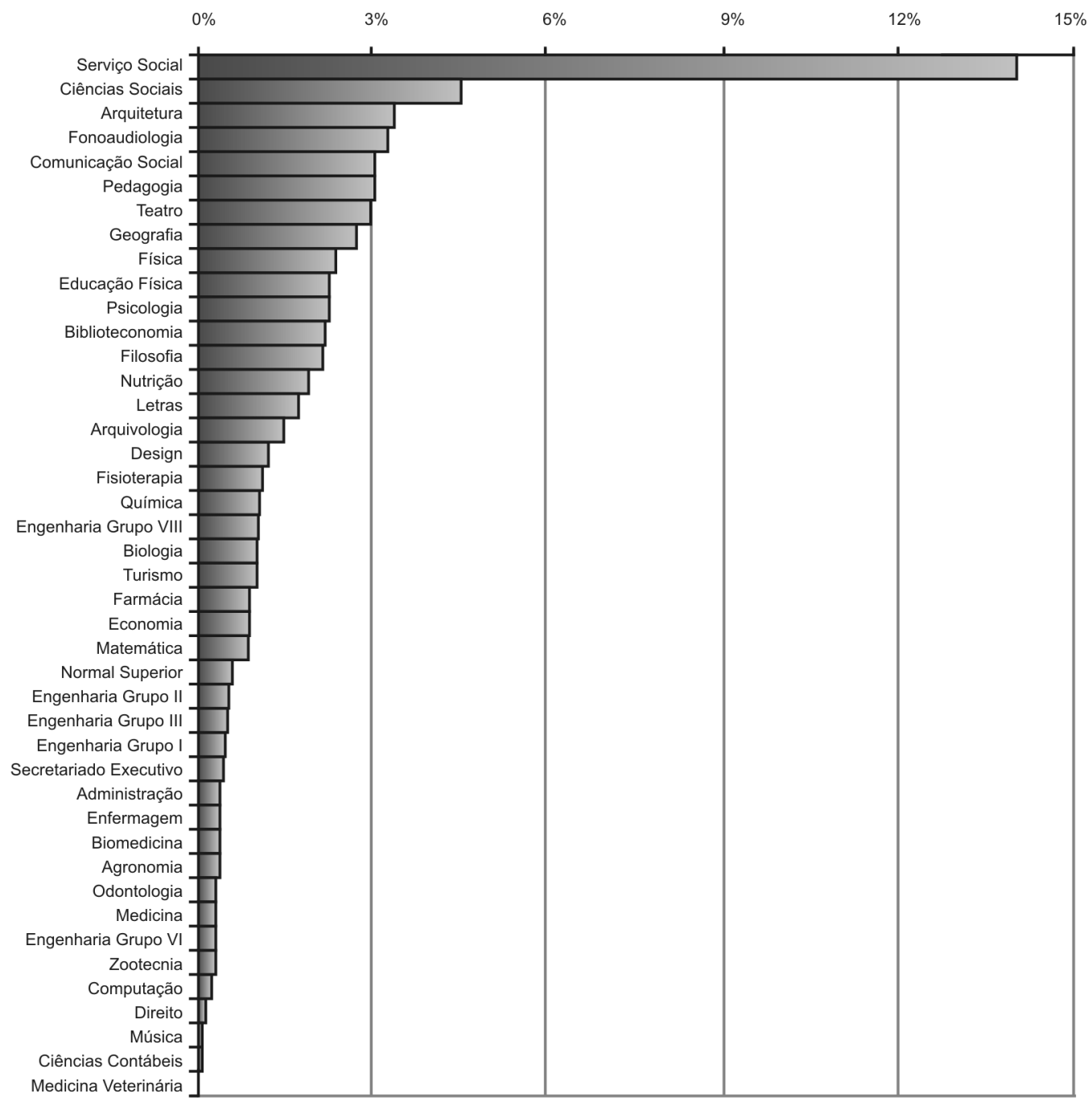


de o curso ser $100 \%$ oferecido por IESs públicas, uma vez que esse fato, por si só, já aumenta a probabilidade de boicote, como mostrado na Figura 8. Com a análise econométrica, o "efeito pública" já foi captado na variável "pública" e assim o impacto isolado do curso torna-se mais "puro". Essa análise serve para todas as outras variáveis do modelo.

\section{Variáveis referentes à condição socioeconômica do aluno}

A análise das variáveis referentes à condição socioeconômica tem por objetivo identificar as características pessoais de cada aluno que estariam relacionadas à probabilidade de esse aluno boicotar. Observa-se nos gráficos seguintes que essas características, em geral, não têm grande correlação com a probabilidade de boicote.

Entre as características pessoais, a renda familiar e a categoria administrativa da escola de ensino médio que o aluno frequentou são as variáveis com maior correlação com a probabilidade de boicote pelo aluno. Os resultados mostram que, quanto maior a renda familiar, maior será a probabilidade de o aluno boicotar, bem como o fato de o aluno ter frequentado a maior parte do ensino médio em escola privada. Mostram ainda que, quanto mais escolarizados forem os pais dos alunos, maior a probabilidade de boicote.

Outras duas variáveis de características pessoais que apresentam certa correlação com a probabilidade de boicote, mas de maneira mais amena, são a "cor da pele" e a "situação ocupacional do aluno". O fato de o aluno ser não branco e não trabalhar apresenta correlação levemente maior na probabilidade de boicote.

Figura 11: Influência da renda na probabilidade de boicote

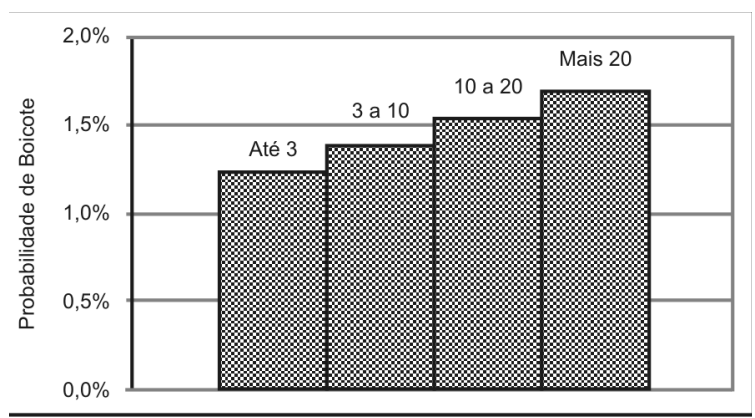

Figura 12: Influência da categoria administrativa da escola onde cursou o ensino médio na probabilidade de boicote

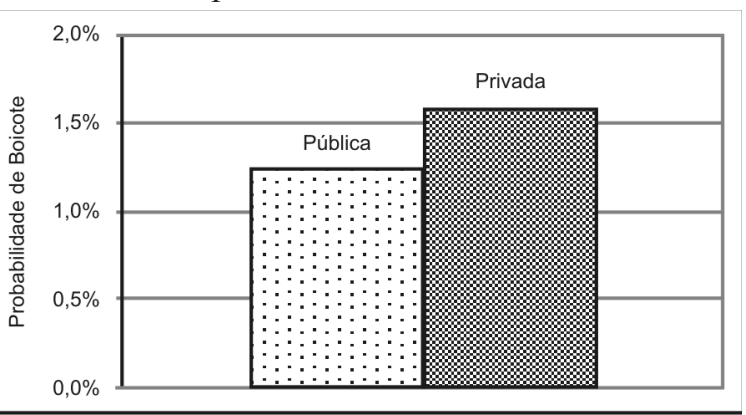

Figura 13: Influência da escolaridade do pai na probabilidade de boicote

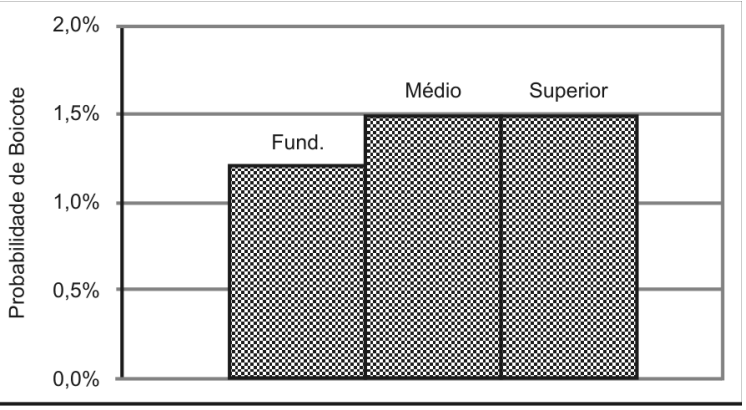

Figura 14: Influência da cor da pele na probabilidade de boicote

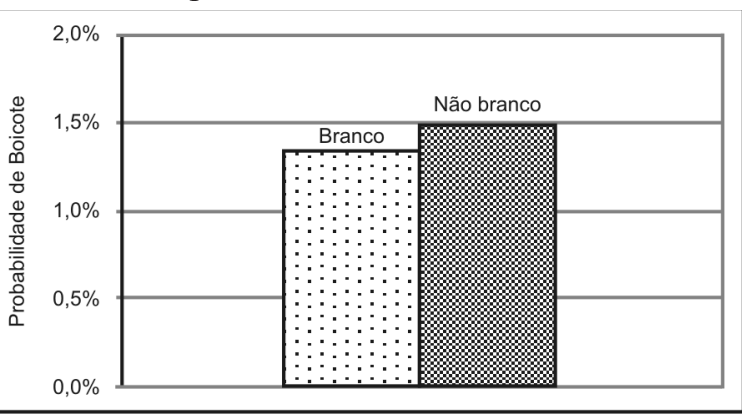

Figura 15: Influência da situação ocupacional na probabilidade de boicote

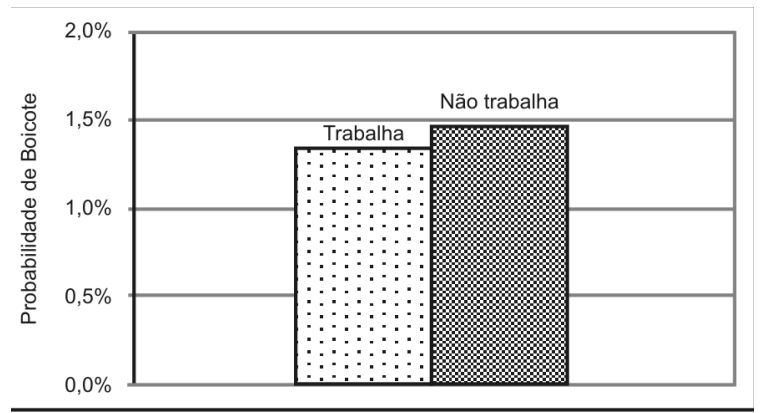




\section{Variáveis referentes à avaliação \\ do aluno sobre a instituição}

Esta análise corrobora os resultados encontrados na Tabela 3. É possível observar a seguir que, quanto pior a avaliação do aluno nos quesitos "instalações físicas", "equipamentos disponíveis", "equipamentos de laboratório" e "currículo do curso", maior a probabilidade de boicote. Esse resultado pode indicar que os alunos que boicotam o exame podem utilizar-se desse meio como forma de explicitar sua insatisfação com o curso e/ou a instituição.

Figura 16: Influência da avaliação das instalações físicas na probabilidade de boicote

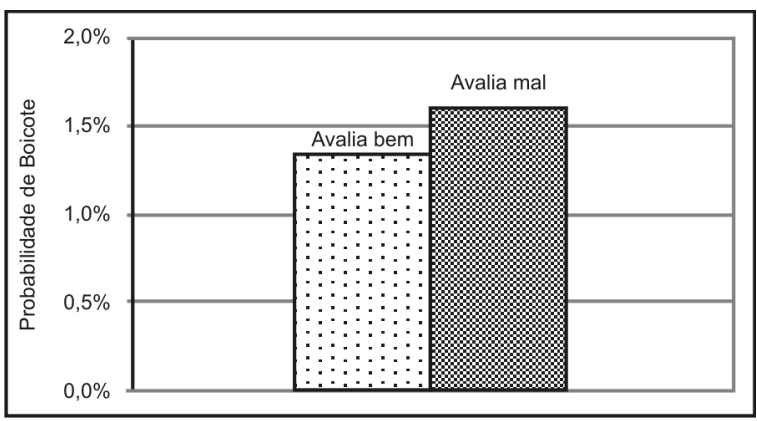

Figura 17: Influência da avaliação dos equipamentos disponíveis na probabilidade de boicote

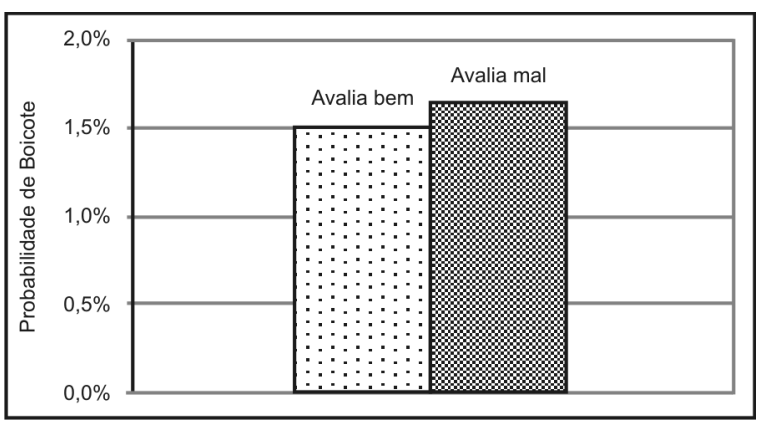

Figura 18: Influência da avaliação dos equipamentos de laboratório na probabilidade de boicote

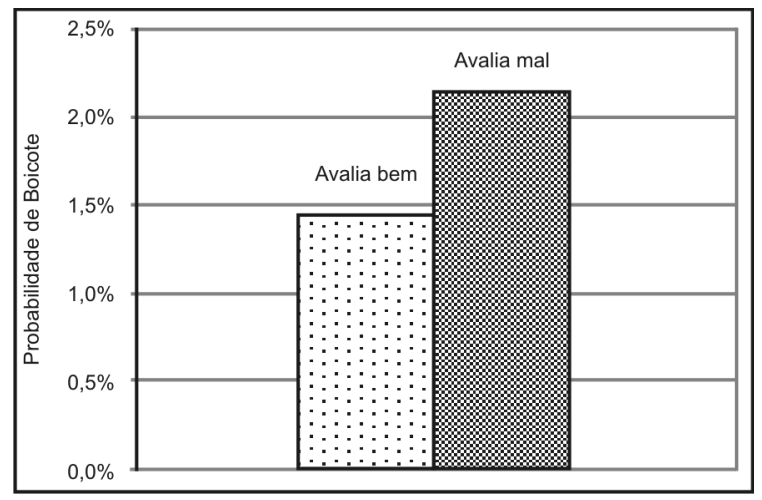

Figura 19: Influência da avaliação do currículo na probabilidade de boicote

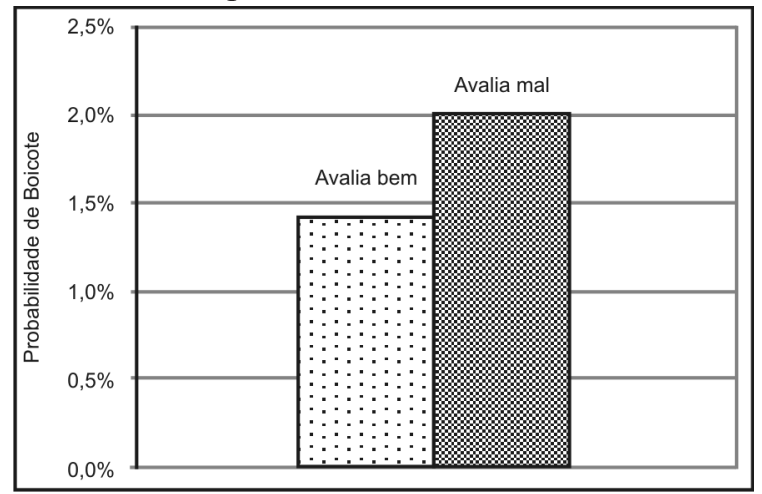

Outra análise que despertou bastante interesse foi com relação à evolução do boicote ao longo do tempo e a identificação de alguma alteração de comportamento influenciada por evento específico em um dos anos da análise (passagem do Provão para o ENADE ou forte campanha pró-boicote de algum movimento estudantil, por exemplo).

Em princípio, pensou-se em agrupar ao banco de dados inicial, para os anos de 1997 a 2004, as mesmas informações levantadas para os anos de 2005, 2006 e 2007, porém alguns problemas de identificação de variáveis e inconsistência de informações foram detectados e optou-se assim por construir um novo banco de dados para os anos de 1999 a 2007. As principais diferenças desse novo banco de dados com o banco utilizado nas análises anteriores são a inclusão de uma variável binária (dummy) de ano e de uma nova variável de situação ocupacional, informando se o indivíduo trabalha ou já tinha trabalhado durante o período do curso - antes essa 
variável informava se o indivíduo estava trabalhando no momento do exame, e a exclusão das variáveis de idade, estado civil, se é ou foi bolsista, assuntos que mais lê no jornal, dedicação acadêmica e percepção dos aspectos físicos, pedagógicos e curriculares do curso.
Uma nova estimação logit foi feita; os resultados podem ser consultados no Anexo C. Para facilitar e exposição desses resultados, adotou-se a mesma metodologia gráfica utilizada anteriormente e os valores encontrados estão representados na Figura 20.

Figura 20: Probabilidade de boicote ao longo dos anos

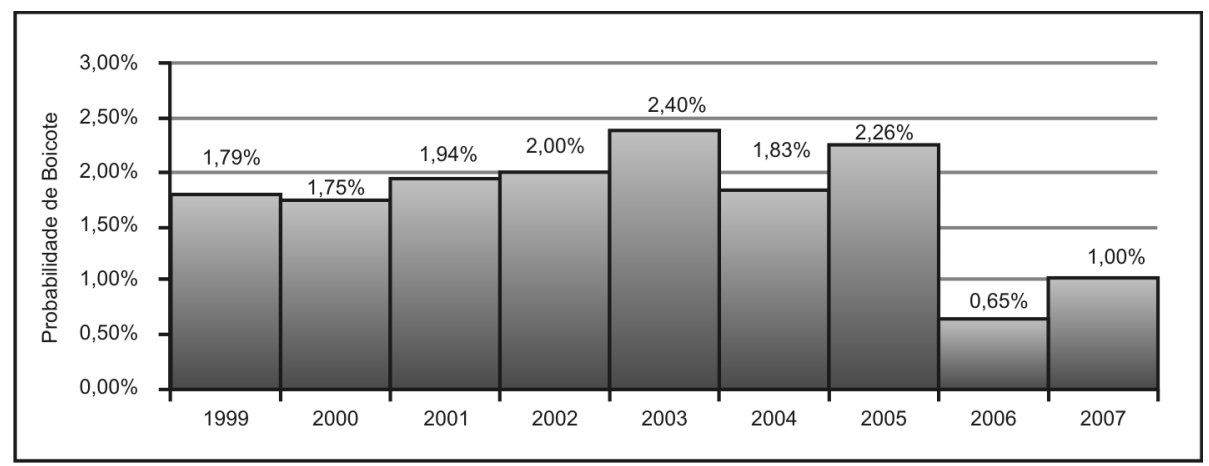

Identificou-se um padrão relativamente constante de boicote ao longo dos anos de 1999 a 2005, sem que houvesse alteração tendencial de comportamento no momento imediatamente após a alteração do sistema de avaliação de Provão para ENADE (em 2004). Interessante notar que essa alteração ocorreu nos anos de 2006 e 2007, mostrando que, pelo menos nos dois últimos anos de ENADE, o fator "ano" assumiu dimensão bastante inferior à demonstrada nos anos anteriores.

\section{Considerações finais}

Este trabalho teve como objetivo analisar o fenômeno popularmente denominado boicote aos exames que compõem o sistema de avaliação do ensino superior, dando ênfase ao ENADE.

Como pôde ser observado, esse comportamento, de forma geral, possui dimensão reduzida, nunca tendo ultrapassado 3,5\% da população avaliada; mas, quando analisado por curso, verificou-se grande variação de incidência, com alguns cursos sendo claramente mais afetados por esse fenômeno.

As estatísticas descritivas demonstraram que o perfil socioeconômico do estudante que adere ao boicote não difere muito do perfil socioeconômico do aluno médio, porém algumas variáveis apresentaram diferenças consideráveis, entre elas a renda familiar, a escolaridade do pai e o tipo de escola em que cursou o ensino médio, mostrando que os boicotantes são alunos com renda familiar mais alta, possuem pais mais escolarizados e cursaram a maior parte do ensino médio em escola privada, quando comparados aos alunos em geral; além disso, esses estudantes avaliam pior seu curso ou sua instituição.

Também puderam ser identificadas neste estudo as diferentes relações que algumas variáveis possuem com a probabilidade de o aluno boicotar. Observou-se que o curso que o aluno frequenta pode relacionar-se com essa probabilidade de forma muito variável. Assim, um aluno que frequenta o curso de Serviço Social, por exemplo, possui probabilidade de boicotar maior cerca de 13 pontos percentuais que um aluno do curso de Medicina Veterinária ou Ciências Contábeis. Além da variável "curso", a categoria administrativa da instituição (pública ou privada), a renda familiar e a categoria administrativa da escola onde o estudante cursou o ensino médio se destacaram das demais na probabilidade de boicote dos alunos.

Outro resultado interessante identificado foi a relação entre a avaliação dos alunos sobre o curso 
ou a instituição que frequentam e a probabilidade de boicote. Foi observado que os alunos que avaliam negativamente os aspectos físicos e curriculares possuem probabilidade de boicote maior do que os alunos que avaliam positivamente. Esse resultado pode indicar que alunos que boicotam o fazem visando demonstrar insatisfação com o curso e/ou a IES.

Por fim, na análise temporal, verificou-se que não houve alteração comportamental no ato de boicotar dos alunos na passagem do Provão para o ENADE (de 2003 para 2004) e que essa alteração foi verificada a partir de 2006.
A busca da descrição, da compreensão e da explicação do fenômeno "boicote" levou a diferentes possibilidades e escolhas para a produção deste material. Mesmo considerando a escassez de bibliografia específica, o presente texto pretendeu elucidar as possíveis relações das diferentes variáveis analisadas com $o$ ato de boicotar. Futuras considerações sobre o tema poderão verificar a intensidade desse comportamento e, a partir daí, atribuir conclusões mais precisas sobre a tendência desse fenômeno.

\section{Anexo A: Variáveis independentes utilizadas na estimação}

Idade (em anos): idade do indivíduo no momento do exame.

Ingressante: variável do tipo dummy assumindo 1, caso o indivíduo fosse ingressante, e 0 , caso o indivíduo fosse concluinte.

Masculino: variável do tipo dummy assumindo 1, caso o indivíduo fosse masculino, e 0 , caso o indivíduo fosse feminino.

Reg_CO: variável do tipo dummy assumindo 1, caso a região de funcionamento do curso do indivíduo fosse a região Centro-Oeste, e 0 , caso contrário.

Reg_NE: variável do tipo dummy assumindo 1, caso a região de funcionamento do curso do indivíduo fosse a região Nordeste, e 0 , caso contrário.

Reg_N: variável do tipo dummy assumindo 1, caso a região de funcionamento do curso do indivíduo fosse a região Norte, e 0 , caso contrário.

Reg_SE: variável do tipo dummy assumindo 1, caso a região de funcionamento do curso do indivíduo fosse a região Sudeste, e 0, caso contrário.

Reg_S: variável do tipo dummy assumindo 1, caso a região de funcionamento do curso do indivíduo fosse a região Sul, e 0 , caso contrário.

Solteiro: variável do tipo dummy assumindo 1, caso o indivíduo fosse solteiro, e 0 , caso contrário.

Branco: variável do tipo dummy assumindo 1, caso o indivíduo se considere branco, amarelo (de origem oriental) ou indígena (de origem indígena), e 0 , caso o indivíduo se considere negro ou pardo/mulato.
Renda_3_sal: variável do tipo dummy assumindo 1, caso a renda mensal da família do indivíduo seja de até 3 salários mínimos, e 0 , caso contrário.

Renda_3_10_sal: variável do tipo dummy assumindo 1, caso a renda mensal da família do indivíduo seja superior a 3 salários mínimos e inferior ou igual a 10 salários mínimos, e 0 , caso contrário.

Renda_10_20_sal: variável do tipo dummy assumindo 1, caso a renda mensal da família do indivíduo seja superior a 10 salários mínimos e inferior ou igual a 20 salários mínimos, e 0 , caso contrário.

Renda_20_mais_sal: variável do tipo dummy assumindo 1, caso a renda mensal da família do indivíduo seja superior a 20 salários mínimos, e 0 , caso contrário.

Trabalha: variável do tipo dummy assumindo 1, caso o indivíduo trabalhe, e 0 , caso o indivíduo não trabalhe.

Bolsa: variável do tipo dummy assumindo 1, caso o indivíduo receba ou tenha recebido algum tipo de bolsa de estudo ou financiamento para custeio das despesas do curso, e 0 , caso contrário. Esc_fund_pai: variável do tipo dummy assumindo 1, caso o grau de escolaridade do pai do indivíduo seja nenhuma escolaridade, ensino fundamental de $1^{\underline{a}}$ a $4^{\underline{a}}$ série ou ensino fundamental de $5^{\mathrm{a}}$ a $8^{\underline{a}}$ série, e 0 , caso contrário.

Esc_medio_pai: variável do tipo dummy assumindo 1, caso o grau de escolaridade do pai do indivíduo seja ensino médio, e 0 , caso contrário.

Esc_sup_pai: variável do tipo dummy assumindo 1, caso o grau de escolaridade do pai do indivíduo seja ensino superior, e 0 , caso contrário.

Esc_fund_mae: variável do tipo dummy assumindo 1, caso o grau de escolaridade da mãe do indivíduo seja nenhuma escolaridade, 
ensino fundamental de $1^{\mathrm{a}}$ a $4^{\mathrm{a}}$ série ou ensino fundamental de $5^{\mathrm{a}} \mathrm{a}$ 8aㅗ série, e 0 , caso contrário.

Esc_medio_mae: variável do tipo dummy assumindo 1, caso o grau de escolaridade da mãe do indivíduo seja ensino médio, e 0 , caso contrário.

Esc_sup_mae: variável do tipo dummy assumindo 1, caso o grau de escolaridade da mãe do indivíduo seja ensino superior, e 0 , caso contrário.

Cursou_em_pub: variável do tipo dummy assumindo 1, caso o indivíduo tenha cursado todo ou a maior parte do ensino médio em escola pública, e 0 , caso contrário.

Cursou_em_priv: variável do tipo dummy assumindo 1, caso o indivíduo tenha cursado todo ou a maior parte do ensino médio em escola privada, e 0 , caso contrário.

Cursou_em_pub_priv: variável do tipo dummy assumindo 1, caso o indivíduo tenha cursado metade do ensino médio em escola pública e metade em escola privada, e 0 , caso contrário.

Assunto_jorn_todos: variável do tipo dummy assumindo 1, caso o assunto de jornal que o indivíduo mais lê seja todos os assuntos, e 0 , caso contrário.

Assunto_jorn_pol_eco: variável do tipo dummy assumindo 1, caso o assunto de jornal que o indivíduo mais lê seja política e/ou economia, e 0 , caso contrário.

Assunto_jorn_cult_art: variável do tipo dummy assumindo 1, caso o assunto de jornal que o indivíduo mais lê seja cultura e arte, e 0 , caso contrário.

Assunto_jorn_esp: variável do tipo dummy assumindo 1, caso o assunto de jornal que o indivíduo mais lê seja esportes, e 0 , caso contrário.

Assunto_jorn_outros: variável do tipo dummy assumindo 1, caso o assunto de jornal que o indivíduo mais lê seja outros, e 0 , caso contrário.

Horas_estudo: variável do tipo dummy assumindo 1, caso o indivíduo tenha dedicado no mínimo uma hora de estudo semanal aos estudos, excetuando as horas de aula, e 0 , caso contrário.

Ativ_acad: variável do tipo dummy assumindo 1, caso o indivíduo tenha desenvolvido algum tipo de atividade acadêmica durante o curso, e 0 , caso contrário.

Proj_pesq: variável do tipo dummy assumindo 1, caso o indivíduo tenha ou tivesse algum envolvimento em projetos de pesquisa, e 0 , caso contrário.
Inst fisicas: variável do tipo dummy assumindo 1, caso o indivíduo tenha avaliado bem as instalações físicas utilizadas no curso, e 0 , caso o indivíduo tenha avaliado mal.

Esp_pedag_bom: variável do tipo dummy assumindo 1, caso o indivíduo tenha considerado adequado o espaço pedagógico em todas ou na maior parte das aulas práticas, e 0 , caso contrário.

Esp_pedag_medio: variável do tipo dummy assumindo 1, caso o indivíduo tenha considerado adequado o espaço pedagógico em metade das aulas práticas, e 0 , caso contrário.

Esp_pedag_mau: variável do tipo dummy assumindo 1, caso o indivíduo tenha considerado adequado o espaço pedagógico em nenhuma ou em menos da metade das aulas práticas, e 0 , caso contrário.

Equip_disp_bom: variável do tipo dummy assumindo 1, caso o indivíduo tenha considerado suficientes os equipamentos disponíveis para o número de estudantes em todas ou na maior parte das aulas práticas, e 0 , caso contrário.

Equip_disp_medio: variável do tipo dummy assumindo 1, caso o indivíduo tenha considerado suficientes os equipamentos disponíveis para o número de estudantes em metade das aulas práticas, e 0 , caso contrário.

Equip_disp_mau: variável do tipo dummy assumindo 1, caso o indivíduo tenha considerado suficientes os equipamentos disponíveis para o número de estudantes em nenhuma ou em menos da metade das aulas práticas, e 0 , caso contrário.

Equip_lab_bom: variável do tipo dummy assumindo 1, caso o indivíduo tenha considerado atualizados e bem conservados os equipamentos de laboratório utilizados no curso, e 0 , caso contrário.

Equip_lab_medio: variável do tipo dummy assumindo 1, caso o indivíduo tenha considerado atualizados mas malconservados ou desatualizados mas bem conservados os equipamentos de laboratório utilizados no curso, e 0 , caso contrário.

Equip_lab_mau: variável do tipo dummy assumindo 1, caso o indivíduo tenha considerado desatualizados e malconservados os equipamentos de laboratório utilizados no curso, e 0 , caso contrário.

Avalia_curr_bom: variável do tipo dummy assumindo 1, caso o indivíduo tenha avaliado o currículo do curso como bem integrado e havendo clara vinculação entre as disciplinas, e 0 , caso contrário.

Avalia_curr_medio: variável do tipo dummy assumindo 1, caso o indivíduo tenha avaliado o currículo do curso como relativamente 
Uma análise acerca do boicote dos estudantes aos exames de avaliação da educação superior

integrado e havendo vinculação entre as disciplinas apenas por blocos ou áreas de conhecimento afins, e 0 , caso contrário.

Avalia_curr_mau: variável do tipo dummy assumindo 1, caso o indivíduo tenha avaliado o currículo do curso como pouco integrado ou sem integração alguma, e 0 , caso contrário.

Plano_ensino_bom: variável do tipo dummy assumindo 1, caso o indivíduo tenha avaliado os planos de ensino como todos ou a maior parte deles contendo objetivos, procedimentos de ensino e de avaliação, conteúdos e bibliografia das disciplinas, e 0 , caso contrário.

Plano ensino medio: variável do tipo dummy assumindo 1, caso o indivíduo tenha avaliado os planos de ensino como apenas cerca da metade deles contendo objetivos, procedimentos de ensino e de avaliação, conteúdos e bibliografia das disciplinas, e 0 , caso contrário.

Plano_ensino_mau: variável do tipo dummy assumindo 1, caso o indivíduo tenha avaliado os planos de ensino como apenas menos da metade ou nenhum deles contendo objetivos, procedimentos de ensino e de avaliação, conteúdos e bibliografia das disciplinas, e 0 , caso contrário.

Prof_dominio_bom: variável do tipo dummy assumindo 1, caso o indivíduo tenha respondido que todos ou a maior parte dos professores tenham demonstrado domínio atualizado das disciplinas ministradas, e 0 , caso contrário.

Prof_dominio_medio: variável do tipo dummy assumindo 1, caso o indivíduo tenha respondido que apenas metade dos professores tenha demonstrado domínio atualizado das disciplinas ministradas, e 0 , caso contrário.

Prof_dominio_mau: variável do tipo dummy assumindo 1, caso o indivíduo tenha respondido que nenhum ou menos da metade dos professores tenha demonstrado domínio atualizado das disciplinas ministradas, e 0 , caso contrário.
Deveria exigir mais: variável do tipo dummy assumindo 1, caso o indivíduo tenha respondido que o curso deveria ter exigido muito mais ou um pouco mais de si, e 0 , caso contrário.

Exigiu_certo: variável do tipo dummy assumindo 1, caso o indivíduo tenha respondido que o curso exigiu na medida certa de si, e 0 , caso contrário.

Deveria_exigir_menos: variável do tipo dummy assumindo 1, caso o indivíduo tenha respondido que o curso deveria ter exigido muito menos ou um pouco menos de si, e 0 , caso contrário.

Contr_curso_diploma: variável do tipo dummy assumindo 1, caso o indivíduo tenha considerado principal contribuição do curso a obtenção de diploma de nível superior, e 0 , caso contrário.

Contr_curso_cultura: variável do tipo dummy assumindo 1, caso o indivíduo tenha considerado principal contribuição do curso a aquisição de cultura geral, e 0 , caso contrário.

Contr_curso_form_prof: variável do tipo dummy assumindo 1, caso o indivíduo tenha considerado principal contribuição do curso a aquisição de formação profissional, e 0 , caso contrário.

Contr_curso_form_teo: variável do tipo dummy assumindo 1, caso o indivíduo tenha considerado principal contribuição do curso a aquisição de formação teórica, e 0 , caso contrário.

Contr_curso_ganho_mat: variável do tipo dummy assumindo 1 , caso o indivíduo tenha considerado principal contribuição do curso a melhoria nas perspectivas de ganhos materiais, e 0 , caso contrário.

Pub: variável do tipo dummy assumindo 1, caso o a categoria administrativa da IES que o indivíduo frequenta seja pública, e 0 , caso seja privada.

Foram incluídas também na análise variáveis dummies de curso, assumindo 1, caso o indivíduo estivesse frequentando aquele respectivo curso, e 0 , caso contrário. 


\section{Anexo B: Resultados da estimação logit para os anos 2005, 2006 e 2007}

\begin{tabular}{|c|c|c|c|c|c|c|}
\hline \multicolumn{2}{|c|}{ Logistic regression } & & & & \multirow{2}{*}{$\begin{array}{c}\text { Number of } \\
\text { obs: } \\
\text { LR chi2(91): }\end{array}$} & \multirow{2}{*}{$\begin{array}{c}488.697 \\
15488,48\end{array}$} \\
\hline & & & & & & \\
\hline & & & & & Prob > chi2: & 0,0000 \\
\hline Log likelihood = -27829,629 & & & & & Pseudo R2: & 0,2177 \\
\hline boicote & Coef. & Std. Err. & $z$ & $\mathrm{P}>|\mathrm{z}|$ & \multicolumn{2}{|c|}{ [95\% Conf. Interval] } \\
\hline Nu_idade & $-0,0046083$ & 0,0028092 & $-1,64$ & 0,101 & $-0,0101143$ & 0,0008977 \\
\hline In_grad & 0,1886378 & 0,0295193 & 6,39 & 0,000 & 0,1307811 & 0,2464945 \\
\hline Masculino & 0,2393122 & 0,0302689 & 7,91 & 0,000 & 0,1799862 & 0,2986382 \\
\hline Reg_CO & $-0,3022254$ & 0,0531693 & $-5,68$ & 0,000 & $-0,4064352$ & $-0,1980156$ \\
\hline Reg_NE & 0,1298866 & 0,0558799 & 2,32 & 0,020 & 0,0203640 & 0,2394093 \\
\hline Reg_SE & $-0,1056635$ & 0,0362097 & $-2,92$ & 0,004 & $-0,1766331$ & $-0,0346938$ \\
\hline $\operatorname{Reg} S$ & $-0,1474006$ & 0,0419550 & $-3,51$ & 0,000 & $-0,2296310$ & $-0,0651703$ \\
\hline Solteiro & 0,1726190 & 0,0439003 & 3,93 & 0,000 & 0,0865760 & 0,2586620 \\
\hline Branco & $-0,1081366$ & 0,0294016 & $-3,68$ & 0,000 & $-0,1657627$ & $-0,0505105$ \\
\hline Renda_3_sal & $-0,3645274$ & 0,0576567 & $-6,32$ & 0,000 & $-0,4775325$ & $-0,2515222$ \\
\hline Renda_3_10_sal & $-0,2209163$ & 0,0506535 & $-4,36$ & 0,000 & $-0,3201953$ & $-0,1216372$ \\
\hline Renda_10_20_sal & $-0,0929666$ & 0,0525309 & $-1,77$ & 0,077 & $-0,1959252$ & 0,0099920 \\
\hline Trabalha & $-0,1340622$ & 0,0290417 & $-4,62$ & 0,000 & $-0,1909829$ & $-0,0771415$ \\
\hline Bolsa & 0,0471746 & 0,0333891 & 1,41 & 0,158 & $-0,0182668$ & 0,1126161 \\
\hline EsC_medio_pai & 0,2239164 & 0,0354026 & 6,32 & 0,000 & 0,1545285 & 0,2933043 \\
\hline EsC_sup_pai & 0,2308147 & 0,0419689 & 5,50 & 0,000 & 0,1485572 & 0,3130721 \\
\hline Esc_medio_mae & 0,1099824 & 0,0362119 & 3,04 & 0,002 & 0,0390084 & 0,1809565 \\
\hline Esc_sup_mae & 0,1375441 & 0,0415055 & 3,31 & 0,001 & 0,0561949 & 0,2188933 \\
\hline Cursou_em_pub & $-0,2860110$ & 0,0311465 & $-9,18$ & 0,000 & $-0,3470570$ & $-0,2249650$ \\
\hline Cursou_em_pub_priv & $-0,1597002$ & 0,0783085 & $-2,04$ & 0,041 & $-0,3131821$ & $-0,0062183$ \\
\hline Assunto_jorn_pol_eco & 0,1775228 & 0,0431213 & 4,12 & 0,000 & 0,0930065 & 0,2620390 \\
\hline Assunto_jorn_cult_art & 0,1572437 & 0,0337436 & 4,66 & 0,000 & 0,0911075 & 0,2233798 \\
\hline Assunto_jorn_esp & $-0,0040395$ & 0,0539302 & $-0,07$ & 0,940 & $-0,1097408$ & 0,1016618 \\
\hline Assunto_jorn_outros & 0,0163991 & 0,0547280 & 0,30 & 0,764 & $-0,0908658$ & 0,1236640 \\
\hline Horas_estudo & $-0,2702436$ & 0,0494494 & $-5,47$ & 0,000 & $-0,3671626$ & $-0,1733247$ \\
\hline Ativ_acad & $-0,0277809$ & 0,0298934 & $-0,93$ & 0,353 & $-0,0863708$ & 0,0308090 \\
\hline Proj_pesq & $-0,1089430$ & 0,0312773 & $-3,48$ & 0,000 & $-0,1702454$ & $-0,0476406$ \\
\hline Inst_fisicas & $-0,1784048$ & 0,0349185 & $-5,11$ & 0,000 & $-0,2468439$ & $-0,1099658$ \\
\hline Esp_pedag_medio & 0,0548556 & 0,0406965 & 1,35 & 0,178 & $-0,0249082$ & 0,1346193 \\
\hline Esp_pedag_mal & 0,1612731 & 0,0410274 & 3,93 & 0,000 & 0,0808608 & 0,2416853 \\
\hline Equip_disp_medio & 0,0995948 & 0,0395624 & 2,52 & 0,012 & 0,0220538 & 0,1771357 \\
\hline Equip_disp_mal & 0,1195990 & 0,0373254 & 3,20 & 0,001 & 0,0464425 & 0,1927554 \\
\hline Equip_lab_medio & 0,3009988 & 0,0324828 & 9,27 & 0,000 & 0,2373337 & 0,3646638 \\
\hline Equip_lab_mal & 0,4545182 & 0,0440147 & 10,33 & 0,000 & 0,3682509 & 0,5407855 \\
\hline Avalia_curr_medio & 0,1515863 & 0,0302678 & 5,01 & 0,000 & 0,0922626 & 0,2109101 \\
\hline Avalia_curr_mal & 0,3770424 & 0,0443474 & 8,50 & 0,000 & 0,2901230 & 0,4639618 \\
\hline Plano_ensino_medio & 0,0223585 & 0,0471866 & 0,47 & 0,636 & $-0,0701256$ & 0,1148426 \\
\hline Plano_ensino_mal & 0,1165189 & 0,0512117 & 2,28 & 0,023 & 0,0161458 & 0,2168920 \\
\hline Prof_dominio_medio & 0,1111397 & 0,0419303 & 2,65 & 0,008 & 0,0289578 & 0,1933217 \\
\hline Prof_dominio_mal & $-0,0061218$ & 0,0572745 & $-0,11$ & 0,915 & $-0,1183778$ & 0,1061341 \\
\hline Deveria_exigir_mais & $-0,0959316$ & 0,0283528 & $-3,38$ & 0,001 & $-0,1515020$ & $-0,0403612$ \\
\hline Deveria_exigir_menos & 0,1517299 & 0,0525410 & 2,89 & 0,004 & 0,0487514 & 0,2547084 \\
\hline
\end{tabular}

(continua) 


\begin{tabular}{|c|c|c|c|c|c|c|}
\hline Contr_curso_diploma & 0,2870609 & 0,0402800 & 7,13 & 0,000 & 0,2081137 & 0,3660082 \\
\hline Contr_curso_cultura & 0,3520399 & 0,0339032 & 10,38 & 0,000 & 0,2855909 & 0,4184889 \\
\hline Contr_curso_form_teo & 0,3777591 & 0,0428718 & 8,81 & 0,000 & 0,2937320 & 0,4617863 \\
\hline Contr_curso_ganho_mat & 0,1858753 & 0,0803000 & 2,31 & 0,021 & 0,0284901 & 0,3432605 \\
\hline Adm & -2.4835220 & 0.1371497 & -18.11 & 0.000 & -2.7523300 & -2.2147130 \\
\hline Direito & $-3,2789140$ & 0,1838295 & $-17,84$ & 0,000 & $-3,6392130$ & $-2,9186140$ \\
\hline Med_vet & $-4,8719260$ & 0,5896466 & $-8,26$ & 0,000 & $-6,0276120$ & $-3,7162400$ \\
\hline Odonto & $-2,6202620$ & 0,2136670 & $-12,26$ & 0,000 & $-3,0390410$ & $-2,2014820$ \\
\hline Matem & $-1,7573500$ & 0,1694511 & $-10,37$ & 0,000 & $-2,0894680$ & $-1,4252320$ \\
\hline Com_social & $-0,4291063$ & 0,1218339 & $-3,52$ & 0,000 & $-0,6678964$ & $-0,1903163$ \\
\hline Letras & $-1,0188300$ & 0,1265775 & $-8,05$ & 0,000 & $-1,2669180$ & $-0,7707429$ \\
\hline Medicina & $-2,6308970$ & 0,1880832 & $-13,99$ & 0,000 & $-2,9995330$ & $-2,2622610$ \\
\hline Econ & $-1,7177110$ & 0,1549149 & $-11,09$ & 0,000 & $-2,0213390$ & $-1,4140830$ \\
\hline Física & $-0,7068528$ & 0,1385360 & $-5,10$ & 0,000 & $-0,9783784$ & $-0,4353271$ \\
\hline Quimica & $-1,4954890$ & 0,1541888 & $-9,70$ & 0,000 & $-1,7976940$ & $-1,1932850$ \\
\hline Biologia & $-1,5305800$ & 0,1321318 & $-11,58$ & 0,000 & $-1,7895530$ & $-1,2716060$ \\
\hline Agronomia & $-2,6178160$ & 0,1978671 & $-13,23$ & 0,000 & $-3,0056290$ & $-2,2300040$ \\
\hline Psico & $-0,7354319$ & 0,1296699 & $-5,67$ & 0,000 & $-0,9895802$ & $-0,4812836$ \\
\hline Farmacia & $-1,7096570$ & 0,1533276 & $-11,15$ & 0,000 & $-2,0101740$ & $-1,4091410$ \\
\hline Pedag & $-0,4326296$ & 0,1256899 & $-3,44$ & 0,001 & $-0,6789773$ & $-0,1862820$ \\
\hline Arquit & $-0,3056375$ & 0,1397772 & $-2,19$ & 0,029 & $-0,5795957$ & $-0,0316792$ \\
\hline Contabeis & $-4,0032740$ & 0,2576671 & $-15,54$ & 0,000 & $-4,5082920$ & $-3,4982560$ \\
\hline Enferm & $-2,5020030$ & 0,1706496 & $-14,66$ & 0,000 & $-2,8364700$ & $-2,1675360$ \\
\hline Historia & $-0,1838793$ & 0,1261897 & $-1,46$ & 0,145 & $-0,4312065$ & 0,0634479 \\
\hline Design & $-1,4153980$ & 0,1560518 & $-9,07$ & 0,000 & $-1,7212540$ & $-1,1095420$ \\
\hline Fono & $-0,3569633$ & 0,1996312 & $-1,79$ & 0,074 & $-0,7482334$ & 0,0343067 \\
\hline Nutricao & $-0,9375089$ & 0,1471122 & $-6,37$ & 0,000 & $-1,2258430$ & $-0,6491743$ \\
\hline Turismo & $-1,5851530$ & 0,1654428 & $-9,58$ & 0,000 & $-1,9094150$ & $-1,2608910$ \\
\hline Geografia & $-0,5459091$ & 0,1289850 & $-4,23$ & 0,000 & $-0,7987150$ & $-0,2931032$ \\
\hline Filo & $-0,7879234$ & 0,2226247 & $-3,54$ & 0,000 & $-1,2242600$ & $-0,3515870$ \\
\hline Ed_fisica & $-0,7306042$ & 0,1271516 & $-5,75$ & 0,000 & $-0,9798169$ & $-0,4813916$ \\
\hline Fisio & $-1,4703920$ & 0,1576114 & $-9,33$ & 0,000 & $-1,7793050$ & $-1,1614790$ \\
\hline Serv_social & 1,4225660 & 0,1261904 & 11,27 & 0,000 & 1,1752380 & 1,6698950 \\
\hline Teatro & $-0,4552893$ & 0,1844736 & $-2,47$ & 0,014 & $-0,8168509$ & $-0,0937276$ \\
\hline Comp & $-2,9851800$ & 0,1903195 & $-15,69$ & 0,000 & $-3,3581990$ & $-2,6121610$ \\
\hline Musica & $-3,8676240$ & 0,5148342 & $-7,51$ & 0,000 & $-4,8766800$ & $-2,8585680$ \\
\hline Zootec & $-2,6898900$ & 0,2591890 & $-10,38$ & 0,000 & $-3,1978910$ & $-2,1818890$ \\
\hline Ter_ocup & 0,0176762 & 0,1807882 & 0,10 & 0,922 & $-0,3366621$ & 0,3720146 \\
\hline Biomedicina & $-2,6000210$ & 0,2444473 & $-10,64$ & 0,000 & $-3,0791280$ & $-2,1209130$ \\
\hline Eng_I & $-2,3258840$ & 0,1724201 & $-13,49$ & 0,000 & $-2,6638210$ & $-1,9879470$ \\
\hline Eng_II & $-2,1522170$ & 0,1504852 & $-14,30$ & 0,000 & $-2,4471630$ & $-1,8572720$ \\
\hline Eng_III & $-2,2551830$ & 0,2005004 & $-11,25$ & 0,000 & $-2,6481570$ & $-1,8622100$ \\
\hline Eng_VI & $-2,6376120$ & 0,2779310 & $-9,49$ & 0,000 & $-3,1823470$ & $-2,0928770$ \\
\hline Eng_VIII & $-1,5274860$ & 0,1866057 & $-8,19$ & 0,000 & $-1,8932270$ & $-1,1617460$ \\
\hline Arquiv & $-1,2129330$ & 0,3078404 & $-3,94$ & 0,000 & $-1,8162890$ & $-0,6095764$ \\
\hline Biblio & $-0,7791334$ & 0,1726131 & $-4,51$ & 0,000 & $-1,1174490$ & $-0,4408179$ \\
\hline Sec_exec & $-2,3900510$ & 0,3391748 & $-7,05$ & 0,000 & $-3,0548210$ & $-1,7252800$ \\
\hline Norm_sup & $-2,1083190$ & 0,2490631 & $-8,46$ & 0,000 & $-2,5964730$ & $-1,6201640$ \\
\hline Pub & 1,6601560 & 0,0333082 & 49,84 & 0,000 & 1,5948730 & 1,7254390 \\
\hline Cons & $-3,5686290$ & 0,1832953 & $-19,47$ & 0,000 & $-3,9278810$ & $-3,2093770$ \\
\hline
\end{tabular}


Anexo C: Resultados da estimação logit para os anos 1999 a 2007

\begin{tabular}{|c|c|c|c|c|c|c|}
\hline \multicolumn{2}{|l|}{ Logistic regression } & & & & \multirow{2}{*}{$\begin{array}{c}\begin{array}{c}\text { Number of } \\
\text { obs: }\end{array} \\
\text { LR chi2(91): }\end{array}$} & \multirow{2}{*}{$\begin{array}{r}2.095 .861 \\
55192,99 \\
\end{array}$} \\
\hline & & & & & & \\
\hline & & & & & Prob > chi2: & 0,0000 \\
\hline $\begin{array}{l}\text { Log likelihood }= \\
-147773,34\end{array}$ & & & & & Pseudo R2: & 0,1574 \\
\hline boicote & Coef. & Std. Err. & $z$ & $\mathrm{P}>|\mathrm{z}|$ & \multicolumn{2}{|c|}{ [95\% Conf. Interval] } \\
\hline Ano_1999 & $-0,32042$ & 0,03016 & $-10,63$ & 0,000 & $-0,37953$ & $-0,26132$ \\
\hline Ano_2000 & $-0,34716$ & 0,02592 & $-13,39$ & 0,000 & $-0,39797$ & $-0,29635$ \\
\hline Ano_2001 & $-0,23569$ & 0,02198 & $-10,72$ & 0,000 & $-0,27877$ & $-0,19262$ \\
\hline Ano_2002 & $-0,19742$ & 0,01882 & $-10,49$ & 0,000 & $-0,23429$ & $-0,16054$ \\
\hline Ano_2004 & $-0,29581$ & 0,03778 & $-7,83$ & 0,000 & $-0,36986$ & $-0,22176$ \\
\hline Aano_2005 & $-0,06522$ & 0,02093 & $-3,12$ & 0,002 & $-0,10624$ & $-0,02420$ \\
\hline Ano_2006 & $-1,39309$ & 0,02795 & $-49,85$ & 0,000 & $-1,44786$ & $-1,33832$ \\
\hline Ano_2007 & $-0,94139$ & 0,03995 & $-23,56$ & 0,000 & $-1,01970$ & $-0,86309$ \\
\hline Masculino & 0,39170 & 0,01300 & 30,13 & 0,000 & 0,36622 & 0,41718 \\
\hline Reg_CO & $-0,04791$ & 0,02285 & $-2,10$ & 0,036 & $-0,09269$ & $-0,00313$ \\
\hline Reg_NE & 0,47730 & 0,01489 & 32,06 & 0,000 & 0,44812 & 0,50648 \\
\hline Reg_N & 0,74828 & 0,02265 & 33,04 & 0,000 & 0,70389 & 0,79267 \\
\hline Reg_S & $-0,24147$ & 0,01764 & $-13,69$ & 0,000 & $-0,27604$ & $-0,20690$ \\
\hline Branco & $-0,14160$ & 0,01335 & $-10,61$ & 0,000 & $-0,16776$ & $-0,11543$ \\
\hline Renda_3_sal & $-0,06357$ & 0,02265 & $-2,81$ & 0,005 & $-0,10797$ & $-0,01917$ \\
\hline Renda_3_10_sal & $-0,04750$ & 0,01872 & $-2,54$ & 0,011 & $-0,08419$ & $-0,01081$ \\
\hline Renda_10_20_sal & $-0,04316$ & 0,01883 & $-2,29$ & 0,022 & $-0,08006$ & $-0,00626$ \\
\hline Trabalhou & $-0,14380$ & 0,01275 & $-11,28$ & 0,000 & $-0,16879$ & $-0,11880$ \\
\hline EsC_medio_pai & 0,29849 & 0,01607 & 18,57 & 0,000 & 0,26699 & 0,32999 \\
\hline EsC_sup_pai & 0,42836 & 0,01818 & 23,56 & 0,000 & 0,39273 & 0,46400 \\
\hline Esc_medio_mae & 0,17971 & 0,01583 & 11,35 & 0,000 & 0,14869 & 0,21074 \\
\hline Esc_sup_mae & 0,33399 & 0,01768 & 18,89 & 0,000 & 0,29933 & 0,36865 \\
\hline Cursou_em_priv & 0,20315 & 0,01361 & 14,93 & 0,000 & 0,17648 & 0,22982 \\
\hline Cursou_em_pub_priv & 0,05484 & 0,03027 & 1,81 & 0,070 & $-0,00449$ & 0,11417 \\
\hline$A d m$ & $-3,86739$ & 0,08644 & $-44,74$ & 0,000 & $-4,03682$ & $-3,69796$ \\
\hline Direito & $-3,01580$ & 0,08033 & $-37,54$ & 0,000 & $-3,17324$ & $-2,85836$ \\
\hline Med_vet & $-3,07905$ & 0,11420 & $-26,96$ & 0,000 & $-3,30288$ & $-2,85522$ \\
\hline Odonto & $-3,65633$ & 0,10660 & $-34,30$ & 0,000 & $-3,86526$ & $-3,44739$ \\
\hline Matem & $-2,47760$ & 0,08727 & $-28,39$ & 0,000 & $-2,64864$ & $-2,30657$ \\
\hline Com_social & 0,33870 & 0,07805 & 4,34 & 0,000 & 0,18573 & 0,49167 \\
\hline Letras & $-1,72781$ & 0,07776 & $-22,22$ & 0,000 & $-1,88023$ & $-1,57540$ \\
\hline Medicina & $-1,92552$ & 0,08246 & $-23,35$ & 0,000 & $-2,08714$ & $-1,76390$ \\
\hline Econ & $-2,14667$ & 0,08682 & $-24,72$ & 0,000 & $-2,31684$ & $-1,97650$ \\
\hline Física & $-0,14377$ & 0,08215 & $-1,75$ & 0,080 & $-0,30479$ & 0,01725 \\
\hline Quimica & $-2,12261$ & 0,09875 & $-21,49$ & 0,000 & $-2,31616$ & $-1,92906$ \\
\hline Biologia & $-1,74551$ & 0,07988 & $-21,85$ & 0,000 & $-1,90207$ & $-1,58895$ \\
\hline Agronomia & $-1,61858$ & 0,08904 & $-18,18$ & 0,000 & $-1,79310$ & $-1,44406$ \\
\hline Psico & $-0,88756$ & 0,07981 & $-11,12$ & 0,000 & $-1,04398$ & $-0,73115$ \\
\hline Farmacia & $-2,36875$ & 0,08939 & $-26,50$ & 0,000 & $-2,54395$ & $-2,19355$ \\
\hline Pedag & $-1,76183$ & 0,07765 & $-22,69$ & 0,000 & $-1,91403$ & $-1,60963$ \\
\hline Arquit & $-1,18282$ & 0,08420 & $-14,05$ & 0,000 & $-1,34786$ & $-1,01779$ \\
\hline
\end{tabular}




\begin{tabular}{|c|c|c|c|c|c|c|}
\hline Contabeis & $-4,29101$ & 0,13475 & $-31,84$ & 0,000 & $-4,55511$ & $-4,02690$ \\
\hline Enferm & $-1,41653$ & 0,08425 & $-16,81$ & 0,000 & $-1,58166$ & $-1,25140$ \\
\hline Historia & $-0,41371$ & 0,07720 & $-5,36$ & 0,000 & $-0,56501$ & $-0,26240$ \\
\hline Design & $-0,70976$ & 0,11731 & $-6,05$ & 0,000 & $-0,93968$ & $-0,47983$ \\
\hline Fono & $-2,02081$ & 0,13113 & $-15,41$ & 0,000 & $-2,27783$ & $-1,76380$ \\
\hline Nutricao & $-1,21224$ & 0,09868 & $-12,28$ & 0,000 & $-1,40565$ & $-1,01884$ \\
\hline Turismo & $-1,20539$ & 0,11586 & $-10,40$ & 0,000 & $-1,43247$ & $-0,97831$ \\
\hline Geografia & $-0,75714$ & 0,08104 & $-9,34$ & 0,000 & $-0,91597$ & $-0,59830$ \\
\hline Filo & $-1,15484$ & 0,13843 & $-8,34$ & 0,000 & $-1,42615$ & $-0,88352$ \\
\hline Ed_fisica & $-0,99337$ & 0,08807 & $-11,28$ & 0,000 & $-1,16597$ & $-0,82076$ \\
\hline Fisio & $-2,83915$ & 0,11480 & $-24,73$ & 0,000 & $-3,06415$ & $-2,61415$ \\
\hline Serv_social & 1,33057 & 0,08626 & 15,42 & 0,000 & 1,16149 & 1,49964 \\
\hline Teatro & 1,06370 & 0,12386 & 8,59 & 0,000 & 0,82093 & 1,30647 \\
\hline Comp & $-3,76097$ & 0,14703 & $-25,58$ & 0,000 & $-4,04915$ & $-3,47279$ \\
\hline Musica & $-2,22640$ & 0,32708 & $-6,81$ & 0,000 & $-2,86748$ & $-1,58533$ \\
\hline Zootec & $-2,71368$ & 0,21070 & $-12,88$ & 0,000 & $-3,12664$ & $-2,30073$ \\
\hline Ter_ocup & $-0,69210$ & 0,12939 & $-5,35$ & 0,000 & $-0,94569$ & $-0,43850$ \\
\hline Biomedicina & $-2,53709$ & 0,19713 & $-12,87$ & 0,000 & $-2,92346$ & $-2,15071$ \\
\hline Eng_l & $-2,51974$ & 0,08948 & $-28,16$ & 0,000 & $-2,69512$ & $-2,34437$ \\
\hline Eng_II & $-2,27893$ & 0,08605 & $-26,48$ & 0,000 & $-2,44759$ & $-2,11027$ \\
\hline Eng_III & $-2,28369$ & 0,09647 & $-23,67$ & 0,000 & $-2,47276$ & $-2,09462$ \\
\hline Eng_IV & $-2,41359$ & 0,12111 & $-19,93$ & 0,000 & $-2,65095$ & $-2,17623$ \\
\hline Eng_V & $-4,44960$ & 1,00374 & $-4,43$ & 0,000 & $-6,41689$ & $-2,48232$ \\
\hline Eng_VI & $-3,33474$ & 0,24165 & $-13,80$ & 0,000 & $-3,80836$ & $-2,86112$ \\
\hline Eng_VIII & $-1,48082$ & 0,15048 & $-9,84$ & 0,000 & $-1,77576$ & $-1,18588$ \\
\hline Arquiv & 0,61071 & 0,21735 & 2,81 & 0,005 & 0,18472 & 1,03670 \\
\hline Biblio & 0,59349 & 0,13432 & 4,42 & 0,000 & 0,33024 & 0,85675 \\
\hline Sec_exec & $-1,56129$ & 0,24385 & $-6,40$ & 0,000 & $-2,03923$ & $-1,08334$ \\
\hline Norm_sup & $-1,95956$ & 0,15956 & $-12,28$ & 0,000 & $-2,27230$ & $-1,64682$ \\
\hline Tec_agro & $-1,38256$ & 0,58841 & $-2,35$ & 0,019 & $-2,53582$ & $-0,22929$ \\
\hline Cons & $-2,49673$ & 0,08050 & $-31,01$ & 0,000 & $-2,65451$ & $-2,33895$ \\
\hline
\end{tabular}

\section{Referências bibliográficas}

BRASIL. Lei n. 9.394, de 20 de dezembro de 1996. Estabelece as Diretrizes e Bases da Educação Nacional. Diário Oficial da União. Brasília, 23 dez. 1996. Disponível em: <http://www.planalto.gov. br/ccivil/LEIS/L9394.htm>. Acesso em: 5 mar. 2009.

. Ministério da Educação. Sistema Nacional de Avaliação da Educação Superior (SINAES): bases para uma nova proposta de avaliação da educação superior. Brasília, 2003.

DIAS, Carmem Lúcia; HORIGUELA, Maria de Lourdes; MARCHELLI, Paulo Sérgio. Políticas para avaliação da qualidade do ensino superior no Brasil: um balanço crítico. Educação e Pesquisa, São Paulo, v. 32, n. 3, dez. 2006. Disponível em: $<$ http://www.scielo.br/scielo.php?script=sci_arttext\&pid=S151797022006000300002\&lng= pt\&nrm=iso $>$. Acesso em: 7 abr. 2009.
HARVEY, Lee; NEWTON, Jethro. Transforming quality evaluation. Quality in Higher Education, London, v. 10, n. 2, p. 149-165, jul. 2004.

INSTITUTO NACIONAL DE ESTUDOS E PESQUISAS EDUCACIONAIS ANÍSIO TEIXEIRA (INEP). Sistema Nacional de Avaliação do Ensino Superior (SINAES). Disponível em: <http:// www.inep.gov.br/superior/sinaes/>. Acesso em: 9 mar. 2009.

PAIVA, Giovanni Silva. Avaliação do desempenho dos estudantes da educação superior: a questão da equidade e obrigatoriedade no Provão e ENADE. Ensaio: Aaval. Pol. Públ. Educ., Rio de Janeiro, v. 16, n. 58, p. 31-46, mar. 2008. Disponível em <http://www.scielo. br/scielo.php?script=sci_arttext\&pid=S0104-40362008000100003$\& \operatorname{lng}=$ pt\&nrm=iso $>$. Acesso em: 9 mar. 2009.

VERHINE, Robert Evan; DANTAS, Lys Maria Vinhaes; SOARES, José Francisco. Do Provão ao ENADE: uma análise 
comparativa dos exames nacionais utilizados no ensino superior brasileiro. Ensaio: Aval. Pol. Públ. Educ., Rio de Janeiro, v. 14, n. 52, p. 291-310, jul./set. 2006.

THIAGO MIGUEL SABINO DE PEREIRA LEITÃO, mestre em economia pela Universidade do Porto, é coordenador geral de Projetos Especiais para Graduação no Instituto de Estudo e Pesquisas Anísio Teixeira, do Ministério da Educação (INEP/ MEC). Publicações recentes: Boletim na Medida (INEP/MEC, ano 1, n. 1, 2, 3, 2009); em coautoria com FERNANDES, R.; PAZELLO, E. T.; MORICONI, G. M. Avaliação de cursos na educação superior: a função e a mecânica do conceito preliminar de curso (INEP, Série Documental, v. 32, p. 5-18, 2009). E-mail: thiago.leitao@mec.gov.br

GABRIELA MIRANDA MORICONI, mestre em administração pública pela Escola de Administração de Empresas de São Paulo da Fundação Getúlio Vargas, é coordenadora geral de Instrumentos e Medidas Educacionais no INEP/MEC. Publicações recentes: Boletim na Medida (INEP/MEC, ano 1, n. 1, 2, 3, 2009); com FERNANDES, R.; PAZELLO, E. T.; LEITÃO, T. M. S. P. Avaliação de cursos na educação superior: a função e a mecânica do conceito preliminar de curso (INEP, Série Documental, v. 32, p. 5-18, 2009); em coautoria com MOURA NETO, J. S.; MARCONI, N.; ARVATE, P. R., Diferentes padrões de políticas salariais nos governos estaduais brasileiros: uma análise a partir do diferencial de salário públicoprivado (Revista de Economia Política, v. 29, n. 3, p. 114-134, jul.
2009); Todos os servidores públicos são bem remunerados? Uma comparação entre as carreiras dos governos estaduais brasileiros (Selecta 2007, edição especial da Revista Economia, p. 149-167, dez.2007).E-mail: gabriela.moriconi@inep.gov.br

MARIÂNGELA ABRÃO, mestre em educação pela Pontifícia Universidade Católica de Campinas, é pesquisadora tecnologista em Informações e Avaliações Educacionais (INEP/MEC). Publicações recentes: Boletim na Medida (INEP, ano 1, n. 1, 2, 3, 2009); em coautoria com SILVA, F. C. M. Matemática básica para decisões administrativas (São Paulo: Atlas, 2007); A sala de aula e a empregabilidade (Revista da Federação das Indústrias de Brasília, n. 2, p. 22-23, 2006); A flexibilização curricular e a inserção no mundo do trabalho (Revista Gestão Universitária, Internet, Brasil, 2005). Pesquisa atual: Flexibilização curricular, no Grupo de Estudos e Pesquisas do Ensino Superior (GEPES) da Faculdade de Educação da Universidade Estadual de Campinas (UNICAMP).E-mail: mariangela.abrao@inep.gov.br

DAYSE SOUZA DA SILVA, mestre em educação pela Universidade Católica de Brasília, é pesquisadora tecnologista em Informações e Avaliações Educacionais (INEP/MEC). Publicações recentes: Boletim na Medida (INEP/MEC, ano 1, n. 1, 2, 3, 2009). E-mail: dayse.silva@inep.gov.br

Recebido em maio de 2009 Aprovado em outubro de 2009 
Thiago Leitão, Gabriela Moriconi, Mariangela Abrão e Dayse Silva

Uma análise acerca do boicote dos estudantes aos exames de avaliação da educação superior

$\mathrm{O}$ artigo analisa o fenômeno denominado boicote aos exames que compõem o sistema de avaliação do ensino superior no Brasil, dando ênfase ao Exame Nacional de Avaliação do Desempenho do Estudante (ENADE). Evidencia a magnitude do fenômeno, ao longo do tempo, entre as instituições públicas e privadas, por tipo de boicote. A análise econométrica realizada tomou como base os dados do último triênio de avaliação do ENADE, identificando as variáveis que mais afetaram a decisão do aluno em adotar esse comportamento, assim como permitindo traçar um perfil do estudante que aderiu ao fenômeno. Como principal conclusão, o estudo mostra que o boicote, quando analisado de uma forma geral, não se mostra significativo, uma vez que o percentual de ocorrência nunca foi superior a 3,5\%; quando analisado por curso, porém, a incidência desse fenômeno apresentou grandes variações. O presente artigo também apresenta algumas possíveis motivações para esse comportamento, entre elas, a insatisfação do aluno com o curso ou com a instituição.

Palavras-chave: avaliação; educação do ensino superior; ENADE; boicote.

\section{An analysis of students' boycott of the higher education assessment} exams

This article examines the phenomenon called boycott of the exams which are part of the evaluation system of higher education in Brazil, highlighting the National Exam for Evaluating Students' Performance (ENADE). It reveals the magnitude of the phenomenon over time, among private and public institutions for type of boycott. Using the last triennial of ENADE, the econo- metric analysis identifies the variables which most influence the student's decision to adopt such an attitude. The analysis also allows us to draw a profile of the students who adhered to the phenomenon. The principal conclusion of the study shows that the boycott, when analyzed in a broad manner, is not significant, since the percentage of occurrence was never higher than $3.5 \%$. However, when examined by course, there was a wide variation of incidence. This article also presents some possible reasons for the boycott, including, among others, the student's dissatisfaction with the course and/or institution.

Key words: evaluation; higher education; ENADE exam; boycott.

\section{Un análisis acerca del boicot de} los estudiantes a los exámenes de evaluación de la enseñanza superior El artículo analiza el fenómeno denominado boicot a los exámenes que componen el sistema de evaluación de la enseñanza superior en Brasil, dando énfasis al Examen Nacional de Evaluación del Desempaño del Estudiante (ENADE). Demuestra la magnitud del fenómeno, a lo largo del tiempo, entre las instituciones públicas y privadas, por el tipo de boicot. El análisis econométrico realizado tomó como base los datos del último trienio de evaluación del ENADE, identificando las variables que más afectaron la decisión del alumno en adoptar este comportamiento, así como permitiendo delinear un perfil del estudiante que se adhirió al fenómeno. Como principal conclusión, el estudio muestra que el boicot, cuando analizado de forma general, no se muestra significativo, una vez que el porcentaje de ocurrencias nunca fue superior al 3,5\%; cuando analizado por curso, sin embargo, la incidencia de ese fenómeno presentó grandes variaciones. El presente artículo también presenta algunas posibles motivacio- nes para ese comportamiento, entre ellas, la insatisfacción del alumno con el curso o con la institución.

Palabras claves: evaluación; educación de la enseñanza superior; ENADE; boicot. 